\title{
High-Altitude (0-100 km) Global Atmospheric Reanalysis System: Description and Application to the 2014 Austral Winter of the Deep Propagating Gravity Wave Experiment (DEEPWAVE)
}

\author{
STEPHEN D. ECKERMANN, ${ }^{\mathrm{a}}$ JUN MA, ${ }^{\mathrm{b}}$ KARL W. HOPPEL,${ }^{\mathrm{c}}$ DAVID D. KuHL,${ }^{\mathrm{c}}$ DOUGlas R. Allen, ${ }^{\mathrm{c}}$ \\ James A. DOyle, ${ }^{\mathrm{d}}$ KeVin C. Viner, ${ }^{\mathrm{d}}$ Benjamin C. Ruston, ${ }^{\mathrm{d}}$ NANCY L. BAKER, ${ }^{\mathrm{d}}$

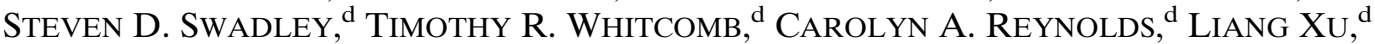 \\ N. KAIfler, ${ }^{\mathrm{e}}$ B. Kaifler, ${ }^{\mathrm{e}}$ IAIN M. Reid ${ }^{\mathrm{f}, \mathrm{g}}$ Damian J. Murphy, ${ }^{\mathrm{h}}$ AND Peter T. Love ${ }^{\mathrm{h}}$ \\ a Space Science Division, U.S. Naval Research Laboratory, Washington, D.C. \\ ${ }^{\mathrm{b}}$ Computational Physics, Inc., Springfield, Virginia \\ ${ }^{\mathrm{c}}$ Remote Sensing Division, U.S. Naval Research Laboratory, Washington, D.C. \\ ${ }^{\mathrm{d}}$ Marine Meteorology Division, U.S. Naval Research Laboratory, Monterey, California \\ ${ }^{\mathrm{e}}$ Institute of Atmospheric Physics, German Aerospace Center, Oberpfaffenhofen, Germany \\ ${ }^{\mathrm{f}}$ ATRAD Pty Ltd, Thebarton, South Australia, Australia \\ ${ }^{\mathrm{g}}$ University of Adelaide, Adelaide, South Australia, Australia \\ ${ }^{\mathrm{h}}$ Department of the Environment and Energy, Australian Antarctic Division, Kingston, Tasmania, Australia
}

(Manuscript received 16 December 2017, in final form 11 May 2018)

\begin{abstract}
A data assimilation system (DAS) is described for global atmospheric reanalysis from 0- to 100-km altitude. We apply it to the 2014 austral winter of the Deep Propagating Gravity Wave Experiment (DEEPWAVE), an international field campaign focused on gravity wave dynamics from 0 to $100 \mathrm{~km}$, where an absence of reanalysis above $60 \mathrm{~km}$ inhibits research. Four experiments were performed from April to September 2014 and assessed for reanalysis skill above $50 \mathrm{~km}$. A four-dimensional variational (4DVAR) run specified initial background error covariances statically. A hybrid-4DVAR (HYBRID) run formed background error covariances from an 80-member forecast ensemble blended with a static estimate. Each configuration was run at low and high horizontal resolution. In addition to operational observations below $50 \mathrm{~km}$, each experiment assimilated $\sim 10^{5}$ observations of the mesosphere and lower thermosphere (MLT) every $6 \mathrm{~h}$. While all MLT reanalyses show skill relative to independent wind and temperature measurements, HYBRID outperforms 4DVAR. MLT fields at 1-h resolution (6-h analysis and 1-5-h forecasts) outperform 6-h analysis alone due to a migrating semidiurnal (SW2) tide that dominates MLT dynamics and is temporally aliased in 6-h time series. MLT reanalyses reproduce observed SW2 winds and temperatures, including phase structures and 10-15-day amplitude vacillations. The $0-100-\mathrm{km}$ reanalyses reveal quasi-stationary planetary waves splitting the stratopause jet in July over New Zealand, decaying from 50 to $80 \mathrm{~km}$ then reintensifying above $80 \mathrm{~km}$, most likely via MLT forcing due to zonal asymmetries in stratospheric gravity wave filtering.
\end{abstract}

\section{Introduction}

The overarching scientific objective of the Deep Propagating Gravity Wave Experiment (DEEPWAVE) was to observe and understand the end-to-end dynamics of gravity waves from the ground to the edge of space at $\sim 100-\mathrm{km}$ altitude (Fritts et al. 2016). This ambitious goal called for a unique combination of high-resolution observations and models specifically targeted to unravel

Corresponding author: Stephen D. Eckermann, stephen. eckermann@nrl.navy.mil gravity wave-generation mechanisms in the troposphere, refraction and filtering of upward-propagating waves by tropospheric and stratospheric winds, and wave instability and breakdown in the mesosphere and lower thermosphere (MLT).

To achieve this science, DEEPWAVE was organized around a major field measurement campaign based out of Christchurch, New Zealand $\left(43.49^{\circ} \mathrm{S}, 172.54^{\circ} \mathrm{E}\right)$, during May-July 2014. During austral winter, this location was identified as a natural laboratory for observing these dynamics due to abundant local orographic and nonorographic sources of gravity waves 


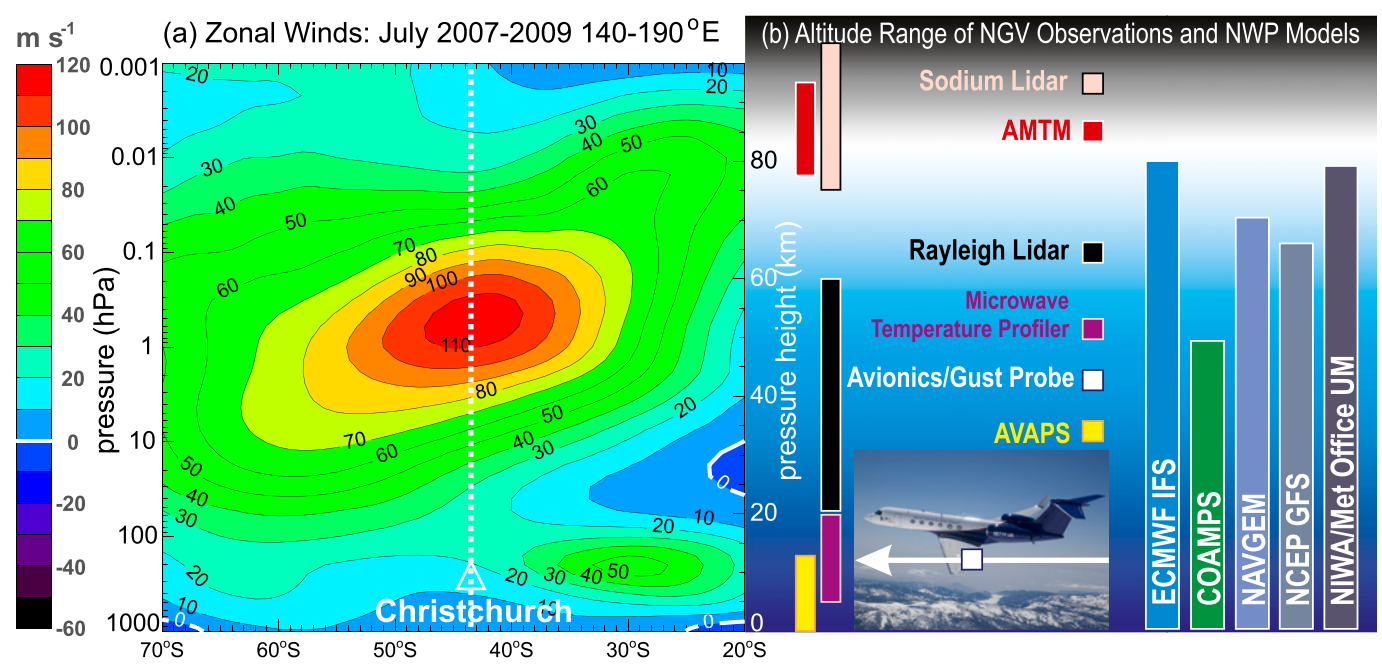

FIG. 1. (a) July zonal winds $\left(\mathrm{m} \mathrm{s}^{-1}\right)$ as a function of pressure (altitude) and latitude averaged over the years $2007-09$ and the longitude zone $140^{\circ}-190^{\circ}$ E near New Zealand from the high-altitude global reanalysis of Eckermann et al. (2009). Dotted white line marks the DEEPWAVE operational base in Christchurch (43.5 ${ }^{\circ}$ ). (b) Altitude ranges of the (left) NGV measurements and (right) operational NWP models available during DEEPWAVE [cf. Tables 2 and 3 of Fritts et al. (2016)].

(e.g., Reeder et al. 1999; Lane et al. 2000; Guest et al. 2000; Zink and Vincent 2001; Smith et al. 2013) and a stable vortex circulation, which, as shown in Fig. 1a, maintains eastward mean winds climatologically from the surface to $\sim 100 \mathrm{~km}$ above Christchurch and surrounding latitudes. Such winds present few critical levels for orographic and nonorographic gravity waves, potentially allowing many to propagate deep into the stratosphere and MLT.

The primary observational platform was the National Science Foundation (NSF)/National Center for Atmospheric Research (NCAR) Gulfstream V research aircraft (NGV; Laursen et al. 2006). As shown in Fig. 1b, during DEEPWAVE, the NGV was equipped with in situ and remote sensing instruments with the necessary vertical range, space-time resolution, and measurement precision to observe gravity wave dynamics over most of the $0-100-\mathrm{km}$ altitude range. NGV observing missions were planned and supported by a suite of gravity waveresolving numerical weather prediction (NWP) systems (Fig. 1b) and by an extensive network of temporary and permanent ground-based observations; for details, see Fritts et al. (2016).

Some of the most spectacular and unanticipated gravity wave events observed during DEEPWAVE occurred in the MLT at $\sim 75-100-\mathrm{km}$ altitude (Kaifler et al. 2015; Bossert et al. 2015; Pautet et al. 2016; Eckermann et al. 2016; Fritts et al. 2016, 2018). Modeling of these observed MLT gravity waves requires accurate knowledge of large-scale winds and temperatures from 0 to $100 \mathrm{~km}$ that control how tropospherically generated wave fields evolve with height into the MLT. While extensive radiosonde and radar soundings at various ground-based sites and dropsonde soundings from the NGV Airborne Vertical Atmospheric Profiling System (AVAPS; Young et al. 2016) provided detailed knowledge of winds and temperatures in the troposphere and lower stratosphere, wind observations were very sparse above $\sim 30 \mathrm{~km}$ (see Table 2 of Fritts et al. 2016).

This common observational restriction is typically overcome through the use of analysis or reanalysis products, which provide an estimate of the state of the atmosphere based on assimilation of available heterogeneous observations using data assimilation systems (DASs). However, as depicted in Fig. 1b, the suite of NWP DASs used during DEEPWAVE all had upper boundaries that did not extend into the MLT. Indeed, at present, no NWP center provides either near-real-time or retrospective analysis products above $60-80-\mathrm{km}$ altitude operationally.

Recognizing this analysis gap above $60-80 \mathrm{~km}$, several groups are developing research prototypes that extend global NWP capabilities into the MLT and higher (e.g., Polavarapu et al. 2005; Wang et al. 2012). The first such prototype to successfully assimilate MLT observations and generate global reanalysis products through the MLT was based on the Navy Operational Global Atmospheric Prediction System (NOGAPS), described in Eckermann et al. (2009); reanalysis winds from that system are plotted in Fig. 1a. In 2012, NOGAPS was replaced by the next-generation Navy Global Environmental Model (NAVGEM; Hogan et al. 2014), and 
similarly motivated research that begins to extend NAVGEM capabilities into the MLT has been reported by Hoppel et al. (2013) and McCormack et al. (2017).

This paper describes a new $0-100-\mathrm{km}$ reanalysis system based around NAVGEM and its use in generating 0-100-km global atmospheric reanalysis products for DEEPWAVE scientific research. The properties of this system and the MLT observations it assimilates are described in section 2. Reanalysis experiments for the 2014 austral winter are outlined in section 3. Reanalyzed temperatures and winds in the MLT are validated against independent observations in section 4 . The $0-100-\mathrm{km}$ reanalysis products are applied in section 5 to delineate aspects of planetary-wave dynamics specific to the greater New Zealand region that potentially impacted MLT gravity waves observed during DEEPWAVE. Major scientific conclusions derived from this reanalysis research are summarized in section 6 .

\section{High-altitude NA VGEM}

\section{a. System overview}

The forecast-assimilation cycle of NAVGEM is depicted schematically in Fig. 2. On the outer loop, the global forecast model, depicted with a red box at the top of Fig. 2 and described in section $2 b(1)$, issues a highresolution deterministic forecast. The 0-9-h forecasts provide a background trajectory $\mathbf{x}^{b}$ (red arrow) to the DAS. The DAS, depicted by the large teal box at the bottom of Fig. 2 and described in section $2 b(2)$, ingests available observations $\mathbf{y}$ (dark blue arrow) acquired within a 3-9-h analysis window as differences $\mathbf{d}$ from this background within the observation space. The DAS cycles internally at a coarser "inner loop" resolution in combining this input vector d of observational innovations, scattered irregularly in space and time, with observational and background errors to form a best linear unbiased estimate (BLUE) of global analysis increments at the central time within the 3-9-h analysis window. These increments are remapped from the inner-loop to the outer-loop grid then added to $\mathbf{x}^{b}$ at $+6 \mathrm{~h}$ to yield the analysis state $\mathbf{x}^{a}$.

As depicted by the teal arrows in Fig. 2, these 6-h analyses are both archived offline and fed back to the forecast model as atmospheric initial conditions for the next update cycle, closing the outer loop, which repeats every $6 \mathrm{~h}$ and generates a new analysis every $6 \mathrm{~h}$. To better resolve tides in the MLT (see section 4), here, we supplement the 6-h analysis with outer-loop forecast backgrounds from the next cycle at 1-h intervals from +1 to $5 \mathrm{~h}$ after initialization to provide a seamless global time series of 1 -h resolution.

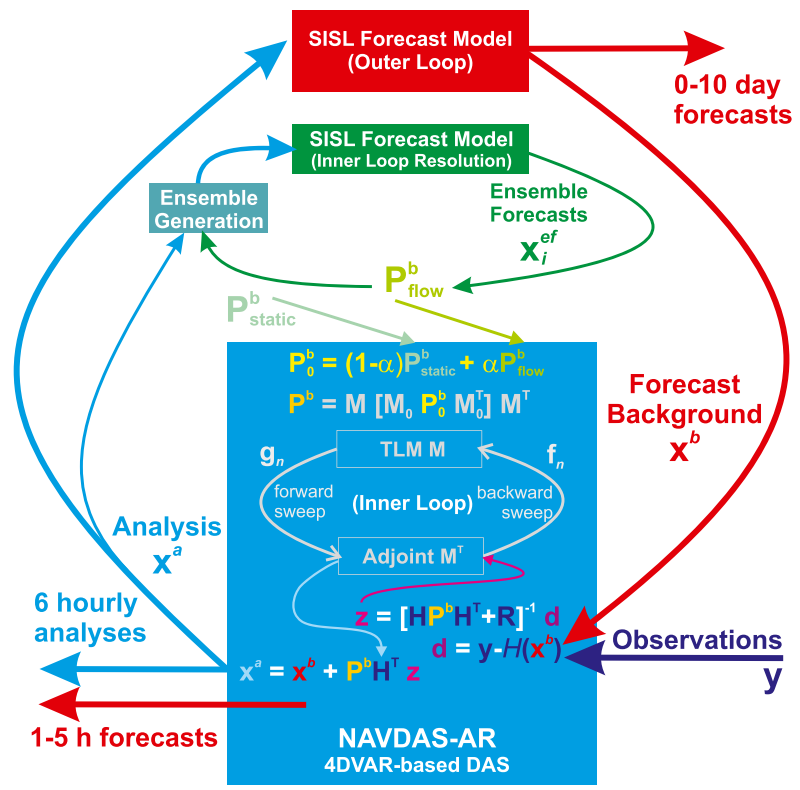

FIG. 2. Schematic depiction of the NAVGEM reanalysis system. See text for explanation of pathways, nomenclature, and mathematical symbols.

\section{b. System components}

\section{1) FORECAST MODEL}

Hogan et al. (2014) provide detailed descriptions of the operational configuration of the forecast model, which is structured around a global, three-time-level (3TL), semi-implicit, semi-Lagrangian (SISL) dynamical core.

In the vertical, the model uses the NEWHYB2 hybrid $\sigma-p$ coordinate of Eckermann (2009). For operational NWP at the Fleet Numerical Meteorology and Oceanography Center (FNMOC), 60 vertical layers (L60) are currently adopted with a rigid upper boundary at $p_{\text {top }}=$ $0.04 \mathrm{hPa}$ (see Fig. 1 of Eckermann et al. 2014). As shown in Fig. 3b, in extending NAVGEM through the MLT, we mirrored those operational L60 levels at pressure altitudes $Z \leqq 50 \mathrm{~km}$, then added layers by smoothly extending layer thicknesses up to a new upper boundary at $p_{\text {top }}=6 \times 10^{-5} \mathrm{hPa}(Z \sim 116 \mathrm{~km})$, for a total of 74 layers (L74). Retaining operational layer thicknesses at $Z \leq$ $50 \mathrm{~km}$ allows this L74 NAVGEM configuration to retain the tuned NWP forecast and analysis skill of the operational L60 system at FNMOC.

Hogan et al. (2014) document the suite of physical parameterizations used in the L60 NAVGEM. Physical parameterizations above $70 \mathrm{~km}$ in the $\mathrm{L} 74$ model will be described more fully in forthcoming publications and so are only briefly summarized here, given this paper's focus on data assimilation. Although new fast 
(a) NAVGEM L74

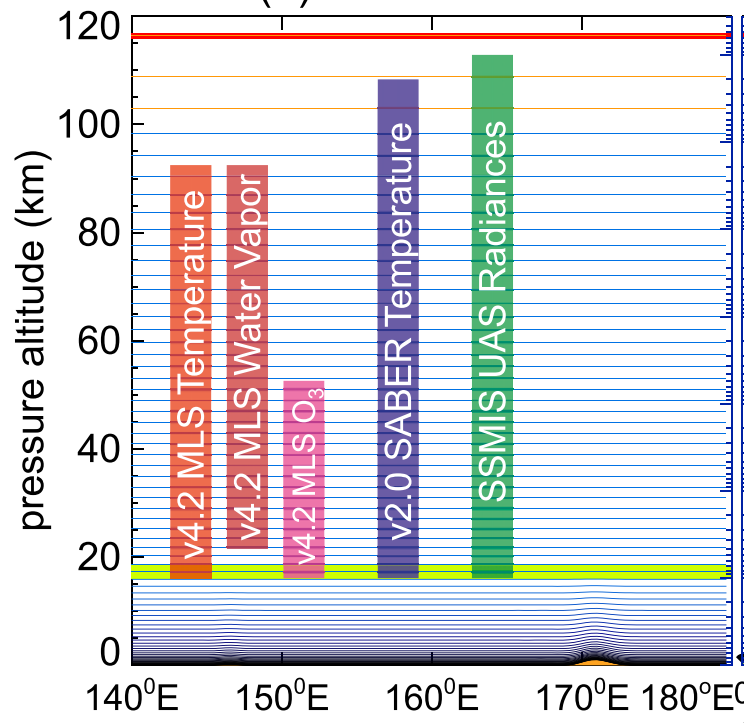

(b) Layer Thicknesses

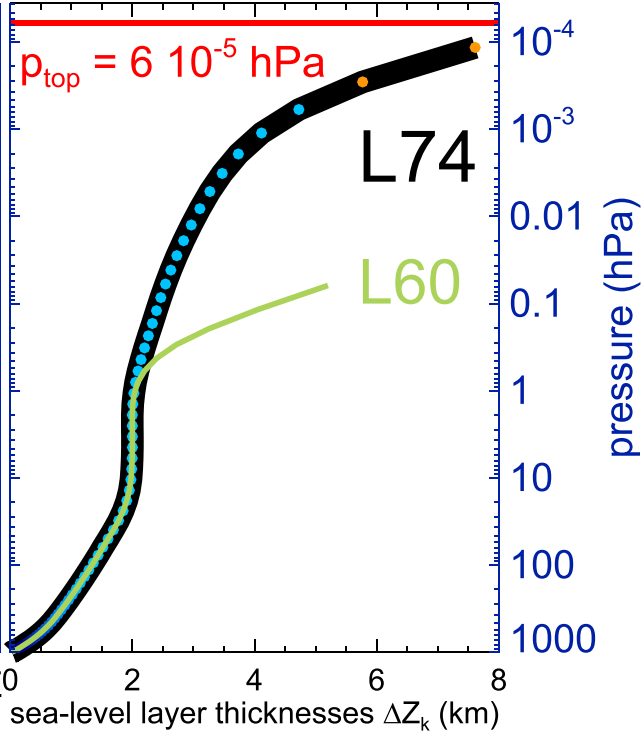

FIG. 3. (a) The 74 NAVGEM $\sigma-p$ levels (L74) shown as interface pressures along a $43.5^{\circ} \mathrm{S}$ latitude circle from $140^{\circ} \mathrm{E}$ to $180^{\circ}$. Note upward displacement of levels over resolved T425 terrain of South Island of New Zealand $\left(\sim 172^{\circ} \mathrm{E}\right)$ and Tasmania $\left(\sim 147^{\circ} \mathrm{E}\right)$. Light green curve shows lowest isobaric model layer at $85 \mathrm{hPa}$. Vertical color bars show approximate altitude ranges of assimilated MLT observations discussed in section 2c. (b) Black curve shows sea level layer thicknesses $\Delta Z_{k}$ vs pressure height $Z$ of the L74 layers shown in (a), with dots located on the full levels. Green curve shows corresponding thicknesses of operational L60 NAVGEM. Orange interface levels in (a) and orange circled full levels in (b) depict heavily diffused upper-level sponge layers. Red line shows rigid upper boundary at $p_{\text {top }}=6 \times 10^{-5} \mathrm{hPa}(Z \sim 116 \mathrm{~km})$.

parameterizations of exothermic chemical heating and radiative heating and cooling modified by breakdown in local thermodynamic equilibrium were available, these schemes are still being tested and refined. For this work, we incorporated simpler temporary lookuptable-based parameterizations of these rates as a function of season, latitude, and height, derived by archiving and averaging rates from a 25 -yr simulation of the specified dynamics version of the Whole Atmosphere Community Climate Model (SD-WACCM), which incorporates detailed parameterizations of UV absorption, chemistry, and species transport (see section 2 of Marsh et al. 2007). Orographic gravity wave drag (OGWD) and flow-blocking drag were parameterized following Webster et al. (2003). Subgrid-scale nonorographic GWD (NGWD) was parameterized using the stochastic scheme of Eckermann (2011). No attempt was made to retune NGWD parameters separately for the different reanalysis runs described in section 3a. The ensemble forecasts described in section $2 b(2)$ employed stochastic kinetic energy backscatter (SKEB), as described in section 2b of Reynolds et al. (2011), but with an additional convective dissipation mask based on moisture convergence (see section $3 \mathrm{~b}$ of Reynolds et al. 2011) that enhances kinetic energy by introducing vorticity perturbations in areas where convective processes are likely to occur.

\section{2) Data ASSimilation AlgORITHM \\ (i) Formulation}

The current NRL Atmospheric Variational DAS (NAVDAS) is based around a four-dimensional variational (4DVAR) algorithm solved in observation space using an accelerated representer (AR) method. An overview of NAVDAS-AR relevant to the $0-100-\mathrm{km}$ NAVGEM is provided here; more complete descriptions of specific aspects are provided elsewhere (see, e.g., Daley and Barker 2001a; Xu et al. 2005; Kuhl et al. 2013; Allen et al. 2014).

By viewing observations $\mathbf{y}$ in terms of a general nonlinear observation operator $H(\mathbf{x})$ applied to (and assumed to be unbiased with respect to) the true atmospheric state $\mathbf{x}$, the input vector of innovations

$$
\mathbf{d}=\mathbf{y}-H\left(\mathbf{x}^{b}\right)
$$

to the DAS (see Fig. 2) represents observed deviations from the forecast background $\mathbf{x}^{b}$. From these innovations, the DAS computes a model correction field by minimizing a scalar cost function $J$. Analysis residuals 
$\mathbf{y}-H\left(\mathbf{x}^{a}\right)$ are minimized via the cost function (Daley and Barker 2001a)

$$
J_{\mathrm{obs}}=\frac{1}{2}\left[\mathbf{y}-H\left(\mathbf{x}^{a}\right)\right]^{\mathrm{T}} \mathbf{R}^{-1}\left[\mathbf{y}-H\left(\mathbf{x}^{a}\right)\right],
$$

where $\mathbf{R}$ is the error covariance matrix of the input observations. The total cost function used here,

$$
J=J_{b_{0}}+J_{\text {obs }},
$$

also accounts for deviations of the analyzed from the background state at the initial time, such that

$$
J_{b_{0}}=\frac{1}{2}\left[\mathbf{x}_{0}^{b}-\mathbf{x}_{0}^{a}\right]^{\mathrm{T}}\left[\mathbf{P}_{0}^{b}\right]^{-1}\left[\mathbf{x}_{0}^{b}-\mathbf{x}_{0}^{a}\right] .
$$

Here, $\mathbf{x}_{0}^{b}, \mathbf{x}_{0}^{a}$, and $\mathbf{P}_{0}^{b}$ are the background state, analysis estimate, and background error covariance matrix, respectively, at the initial time $t_{0}$ of the analysis window.

The path to DA solutions involves linearizing observation and model operators. For example, $H\left(\mathbf{x}^{a}\right)$ is approximated by a truncated Taylor series expansion around the background trajectory $\mathbf{x}^{b}$, such that

$$
H\left(\mathbf{x}^{a}\right)=H\left(\mathbf{x}^{b}\right)+\mathbf{H}\left[\mathbf{x}^{a}-\mathbf{x}^{b}\right],
$$

where the matrix $\mathbf{H}$ is the Jacobian of the observation operator at $\mathbf{x}^{b}$. Representing the forecast model as a nonlinear operator $M$, such that forecast states $\mathbf{x}_{n}^{f}=M\left(\mathbf{x}_{n-1}^{f}\right)$, where the index $n$ denotes discrete successive forecast times $t_{n-1}$ and $t_{n}$, then linearizing $M$ around the background trajectory $\mathbf{x}^{b}$ yields

$$
\mathbf{x}_{n}^{f}=\mathbf{x}_{n-1}^{b}+\mathbf{M}_{n-1}\left[\mathbf{x}_{n-1}^{f}-\mathbf{x}_{n-1}^{b}\right],
$$

where $\mathbf{M}_{n-1}$ is the tangent linear form of the forecast model (TLM) at $\mathbf{x}_{n-1}^{b}$. The current NAVGEM TLM and adjoint use a linearized Eulerian spectral core (Rosmond 1997); a new TLM based on a linearized SISL core is currently being evaluated.

Given an error covariance matrix for the background trajectory $\mathbf{P}^{b}$ (discussed below) and the adjoints $\mathbf{M}^{\mathrm{T}}$ and $\mathbf{H}^{\mathrm{T}}$, the BLUE AR solution that minimizes the imposed cost functions is (Xu et al. 2005)

$$
\begin{aligned}
\mathbf{x}^{a}-\mathbf{x}^{b} & =\mathbf{P}^{b} \mathbf{H}^{\mathrm{T}}\left[\mathbf{H} \mathbf{P}^{b} \mathbf{H}^{\mathrm{T}}+\mathbf{R}\right]^{-1} \mathbf{d}, \\
& =\mathbf{P}^{b} \mathbf{H}^{\mathrm{T}} \mathbf{z},
\end{aligned}
$$

where

$$
\mathbf{P}^{b}=\mathbf{M}\left[\mathbf{M}_{0} \mathbf{P}_{0}^{b} \mathbf{M}_{0}^{\mathrm{T}}+\mathbf{Q}\right] \mathbf{M}^{\mathrm{T}} .
$$

As depicted in Fig. 2, this AR solution converts the input innovations $\mathbf{d}$ in the observation space into output analysis increments $\mathbf{x}^{a}-\mathbf{x}^{b}$ in the model (analysis) space. The matrix $\mathbf{Q}$ is the error covariance of the forecast model. Here, $\mathbf{Q}$ is set to be the zero matrixa "perfect model" assumption that yields a so-called "strong constraint" 4DVAR solution (Xu et al. 2007) and simplifies the cost function $J$ to the form given by (3).

\section{(ii) Numerical solvers}

Numerical evaluation of (7) involves an iterative solver for the analysis residual $\mathbf{z}$ in the observation space, followed by the postmultiplication (8) to produce increments. Both involve numerical evaluations of

$$
\mathbf{g}=\mathbf{P}^{b} \mathbf{H}^{\mathrm{T}} \mathbf{p}
$$

for an input vector $\mathbf{p}$. Given the time-evolved form for $\mathbf{P}^{b}$ in (9), then, as depicted in Fig. 2, (10) is evaluated via one backward then one forward "sweep" of the TLM adjoint and TLM, respectively, through all times $t_{n}$ within the analysis window. Subject to the initial condition $\mathbf{f}_{N}=\mathbf{H}_{N}^{\mathrm{T}} \mathbf{p}_{N}$ at the end time $t_{N}, \mathbf{f}=\mathbf{H}^{\mathrm{T}} \mathbf{p}$ is computed at all earlier $t_{n}$ within the analysis window during the backward sweep as

$$
\mathbf{f}_{n}=\mathbf{M}_{n}^{\mathrm{T}} \mathbf{f}_{n+1}+\mathbf{H}_{n}^{\mathrm{T}} \mathbf{p}_{n} .
$$

Then, $\mathbf{g}=\mathbf{P}^{b} \mathbf{f}$ is calculated at all $t_{n}$, subject to the boundary condition $\mathbf{g}_{0}=\mathbf{P}_{0}^{b} \mathbf{f}_{0}$ at the start time $t_{0}$, during the forward sweep as

$$
\mathbf{g}_{n}=\mathbf{M}_{n-1} \mathbf{g}_{n-1}+\mathbf{Q}_{n} \mathbf{f}_{n} .
$$

Multiple sweep cycles are involved in solving iteratively for $\mathbf{z}$ using a conjugate gradient descent method, with preconditioners to improve convergence (Daley and Barker 2001b; Xu et al. 2005; Chua et al. 2009). A simple preconditioner is applied for the first outer loop, which builds up during the first inner-loop iteration via the preconditioned conjugate gradient and is applied on the next outer loop. The solution is accepted when the norm $\|\nabla J\|$ falls to $\leq 0.05$ of its initial value (Daley and Barker 2001b). Inserting this $\mathbf{z}_{n}$ solution as the input $\mathbf{p}$ in (10) yields-via (8), (11), and (12) - the analysis increments $\mathbf{x}_{n}^{a}-\mathbf{x}_{n}^{b}=\mathbf{g}_{n}$. Note that the analysis $\mathbf{x}_{n}^{a}$ is provided at all times $t_{n}$ within the analysis window and so can provide analysis time series at 1 -h resolution for resolving tides, a capability tested recently in NAVGEM for analysis-based atmospheric angular momentum calculations for naval time-keeping applications (Baker and Langland 2017). Given our need for a well-validated configuration giving reliably accurate atmospheric reanalysis products at all altitudes for scientific research applications, we retained the 
standard operational configuration that saves analysis at the central time only and supplemented the intervening 1-h intervals between 6-h update cycles with outer-loop 1-5-h forecast backgrounds, as depicted in Fig. 2.

\section{(iii) Digital filter}

Analysis errors lead to spurious imbalances, which, when passed to the forecast model as atmospheric initial conditions, can trigger spontaneous emission of resolved gravity waves. In high-altitude models, this gravity wave noise propagates deep into the MLT, where it attains large amplitudes and often breaks, driving deleterious upscale impacts on analyzed mean and tidal structures (e.g., Sankey et al. 2007; Nezlin et al. 2009b). Standard methods for removing spurious imbalances, such as nonlinear normal-mode initialization (NNMI) and digital filters, perform poorly when applied directly to highaltitude analyses, since they distort tides and suppress geophysical gravity waves (Wergen 1989; Sankey et al. 2007). Conversely, applying these filters to analysis increments effectively removes noise while better preserving geophysical mean, tidal, and gravity wave features at all altitudes (Ballish et al. 1992; Seaman et al. 1995; Courtier et al. 1998; Sankey et al. 2007; Buehner et al. 2015).

While a previous version of our high-altitude analysis system used incremental NNMI (Eckermann et al. 2009), NNMI has been superseded in NAVGEM by a digital filter of the Lanczos form (see section 3a of Lynch and Huang 1992), which is applied to timeevolved increments from the TLM forward sweep of the final $z_{n}$ solution. Following Lynch and Huang (1992), this incremental digital filter (IDF) is applied within the \pm 3 -h forward-sweep window via a forward TLM integration from 0 to $+3 \mathrm{~h}$ and a reverse TLM integration from 0 to $-3 \mathrm{~h}$. Tests indicate that our 4DVAR system produces less spurious unbalanced motion in analyses that affect the MLT relative to our previous 3DVAR system (see Eckermann et al. 2009), and that digital filtering of increments within the final inner-loop TLM cycle is effective at suppressing gravity wave noise, consistent with the findings of Gauthier and Thépaut (2001) and Sankey et al. (2007). We use a cutoff period of $6 \mathrm{~h}$ for the IDF based inter alia on the MLT experiments of Sankey et al. (2007) and Nezlin et al. (2009a).

\section{(iv) Specifying $\mathbf{P}_{0}^{b}$}

In the standard NAVDAS-AR algorithm, initial background error covariances $\mathbf{P}_{0}^{b}$ in (4) and (9) are specified statically using the form (Daley and Barker 2001a; Kuhl et al. 2013)

$$
\mathbf{P}_{\text {static }}^{b}=\mathbf{D}_{\text {static }}^{1 / 2} \mathbf{C}_{\text {static }} \mathbf{D}_{\text {static }}^{1 / 2}
$$

where $\mathbf{D}_{\text {static }}$ is a diagonal matrix of static error variances. For meteorological variables, a constant surface wind error of $1.5 \mathrm{~m} \mathrm{~s}^{-1}$ is specified, then converted into meridionally varying errors in surface geopotential height and virtual temperature using geostrophic and hydrostatic balance, respectively, along with prespecified horizontal and vertical correlation scales and vertical variations in temperature error (Daley and Barker 2001b). Zonal-mean values of these static temperature and horizontal wind errors in the L74 NAVGEM are shown in Figs. $4 a$ and $4 b$, respectively.

The matrix $\mathbf{C}_{\text {static }}$ specifies various horizontal and vertical correlations among variables, complete descriptions of which can be found in sections 3.8 and 4 and appendix B of Daley and Barker (2001a) and in section 2.2 of Allen et al. (2014). Figure 4e shows the vertical correlation of geopotential (temperature) errors, the width of which increases with height, consistent with a similar broadening of model layers with height in Fig. 3b and in dominant vertical scales of resolved gravity wave motion (Smith et al. 1987).

One off-diagonal correlation of particular relevance to this study is the coupling between rotational and geostrophic winds. Since geostrophic winds are specified diagnostically from horizontal gradients in geopotential (temperature), this correlation allows assimilated temperature information to produce rotational wind increments. Following Lorenc (1981), the strength of this coupling is prescribed by a correlation coefficient $\mu$, where $|\mu|=1(|\mu|=0)$ denotes complete (no) coupling. Figure 4f plots the meridional variation of $\mu$ prescribed statically in NAVDAS-AR, with near-perfect coupling at high latitudes and zero coupling at the equator where the diagnostic $f$-plane geostrophic relation breaks down.

While geostrophic coupling of temperature increments into a balanced wind response is often a good approximation in the troposphere and stratosphere, this balance breaks down in the MLT (e.g., McLandress et al. 2006), where local wind and temperature responses are dominated by divergent (unbalanced) tidal and gravity wave motions (Koshyk et al. 1999). Static diagnostics relating temperature and wind can be avoided in the MLT to some extent by utilizing a new hybrid 4DVAR capability within NAVGEM (Kuhl et al. 2013). In hybrid 4DVAR, initial background covariances need not be specified diagnostically and statically, but can instead be specified numerically and variably from ensemble forecasts performed at the inner-loop resolution. This new ensemble component to the system is depicted by the green loop in Fig. 2. Perturbed analyses as initial conditions for the ensemble forecasts are generated 

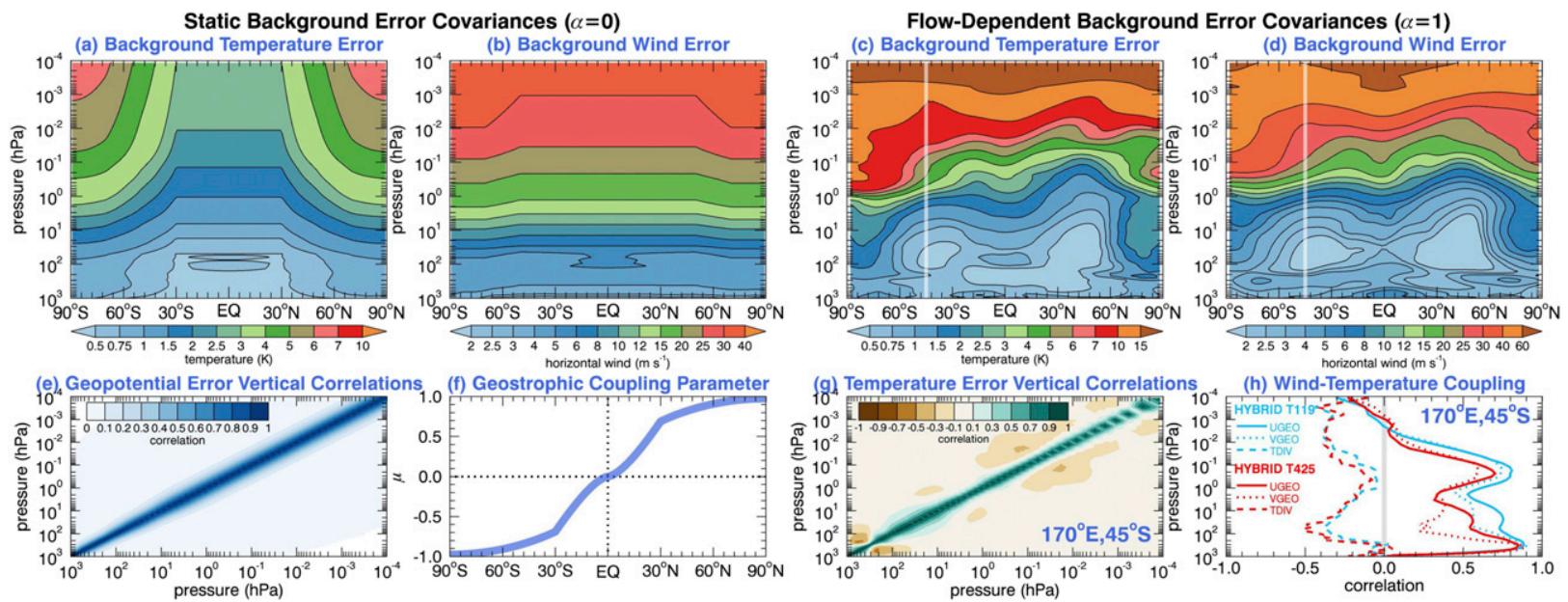

FIG. 4. Aspects of the static background error covariances $\mathbf{P}_{\text {static }}^{b}$. Zonal-mean errors in (a) temperature and (b) horizontal wind vs latitude and pressure; (e) vertical correlation of geopotential (temperature) error vs pressure; (f) correlation coefficient $\mu$ between horizontal gradients in geopotential (geostrophic wind) and rotational wind. Related properties of flow-dependent background error covariances $\mathbf{P}_{\text {flow }}^{b}$ averaged throughout July 2014. Zonal-mean standard deviations of (c) temperature and (d) horizontal wind perturbations from HYBRID T119 inner-loop (T47) ensemble forecasts. White line marks a point at $45^{\circ} \mathrm{S}, 170^{\circ} \mathrm{E}$, where results in lower two panels are computed: (g) Vertical correlation of temperature perturbations and (h) height variation of mean correlation coefficients between geostrophic and rotational wind perturbations in the zonal (UGEO; solid) and meridional (VGEO; dotted) directions and between perturbations in temperature and divergence (TDIV; dashed) for HYBRID119 (aqua) and HYBRID425 (red).

from 6-h ensemble forecast perturbations from the previous cycle using a local form of the ensemble transform algorithm used in the operational ensemble prediction system (McLay et al. 2010), with modifications as noted in section 3 of Kuhl et al. (2013). An initial background error covariance is computed from the resulting inner-loop ensemble forecasts at $t_{0}=3 \mathrm{~h}$ as

$$
\mathbf{P}_{\text {flow }}^{b}=\left[\frac{1}{n_{e_{f}}-1} \sum_{i=1}^{n_{e_{f}}}\left(\mathbf{x}_{i}^{e_{f}}-\bar{x}_{f}^{e_{f}}\right)\left(\mathbf{x}_{i}^{e_{f}}-\overline{\mathbf{x}}_{f}^{e_{f}}\right)^{\mathrm{T}}\right] \circ \mathbf{L},
$$

where $n_{e_{f}}$ is the total number of ensemble forecast members (here set to 80 ), $\mathbf{x}_{i}^{e_{f}}$ is ensemble forecast member $i, \overline{\mathbf{x}}^{e_{f}}$ is the ensemble-mean forecast, the open circle denotes the Schur matrix product [see section 4.6.2 of Daley and Barker (2001a)], and $\mathbf{L}$ is a localization matrix used to remove spurious remote spatial correlations due to an insufficient number of ensemble members. Kuhl et al. (2013) discuss the vertical and horizontal correlation functions used to specify L. Aspects of the flow-dependent covariances are shown in Fig. 4 and are discussed in section $3 b$.

The initial background error covariance in (9) in the hybrid 4DVAR NAVGEM is

$$
\mathbf{P}_{0}^{b}=(1-\alpha) \mathbf{P}_{\text {static }}^{b}+\alpha \mathbf{P}_{\text {flow }}^{b},
$$

where $0 \leq \alpha \leq 1$, such that $\alpha=0$ reproduces the static initial error covariances of the original 4DVAR system, and $\alpha=1$ replaces those with initial "errors of the day" specified entirely from the inner-loop forecast ensemble. Our choices for $\alpha$ are discussed in section 3a.

\section{c. Assimilated MLT observations}

The heterogeneous tropospheric and stratospheric observations assimilated by NAVGEM for operational NWP (e.g., Hoover and Langland 2016; Campbell et al. 2017) are also assimilated here. Here, we focus on additional observations assimilated above $\sim 50-\mathrm{km}$ altitude for this work, as depicted graphically in Fig. 3a. We leverage and extend assimilation capabilities for these sensors developed via previous high-altitude Navy reanalysis research (e.g., Hoppel et al. 2008; Eckermann et al. 2009; Hoppel et al. 2013) and discuss below only relevant changes for the new reanalysis experiments reported here.

\section{1) MLS AND SABER LIMB RETRIEVALS}

We assimilate temperatures from the Microwave Limb Sounder (MLS) on NASA's Aura satellite (Schwartz et al. 2008) and the Sounding of the Atmosphere using Broadband Emission Radiometry (SABER) instrument on NASA's Thermosphere, Ionosphere, Mesosphere Energetics and Dynamics (TIMED) satellite (Remsberg et al.2008). In earlier work, we assimilated temperatures from version 2 (v2) MLS and v1.06 and v1.07 SABER retrievals (Hoppel et al. 2008; Eckermann et al. 2009; Hoppel et al. 2013). Improved data from new retrieval 
versions have since appeared. The v3 and v4 MLS retrievals mainly improve the upper troposphere and lower stratosphere, as well as provide temperatures on a finer-altitude grid (Yan et al. 2016). SABER v2.0 retrievals incorporate better radiometric calibration and improved nonlocal thermodynamic equilibrium (LTE) retrievals that lead to less data rejection (higher data rates) and extend temperatures to higher altitudes (Rezac et al. 2015). Thus, here, we assimilate v4 MLS temperatures from 100 to $0.002 \mathrm{hPa}$ and $\mathrm{v} 2.0$ SABER temperatures from 100 to $2 \times 10^{-4} \mathrm{hPa}$. Initial NAVGEM reanalysis runs described in Eckermann et al. (2016) assimilated v3 MLS temperatures because the newer v4.2 retrievals were not yet available for all observation days in 2014.

Previous comparisons of v2 MLS and v1 SABER temperatures revealed height-dependent mean biases (e.g., Schwartz et al. 2008; Remsberg et al. 2008; Hoppel et al. 2008; Eckermann et al. 2009). Thus, we recomputed mean biases between MLS and SABER temperatures for all available retrieval versions. Differences were studied via MLS-SABER coincidences, defined as profile pairs separated in local time by $\leq 1 \mathrm{~h}$ and horizontally by great circle distances $\leq 200 \mathrm{~km}$. SABER temperatures were linearly interpolated onto the MLS pressure grid, and coincident difference profiles were averaged over the years 2005-12 for v1.07 SABER, 2005-14 for v2.0 SABER and v2 and v3 MLS, and $2005-15$ for v2.0 SABER and v4 MLS. Globalmean biases are plotted in Fig. 5, showing a reproducible mean bias profile over all MLS and SABER retrieval versions. Consistent with previous studies (e.g., Schwartz et al. 2008), we found little seasonal or latitudinal variation in this bias. Note in particular from Fig. 5 the large increases in coincidence data with v2.0 SABER, due to higher raw data acceptance rates in v2.0 temperature retrievals relative to earlier versions.

We use the v4 MLS-v2.0 SABER mean bias profile (red curve in Fig. 5) within NAVGEM to correct SABER temperatures from 68 to $5 \mathrm{hPa}$, given evidence of a SABER warm bias at these altitudes (Remsberg et al. 2008; García-Comas et al. 2014). After bias correction, three-point vertical smoothing is applied to SABER profiles, with additional three-point smoothing at levels above $1 \mathrm{hPa}$ to produce profile resolutions more similar to layer thicknesses in Fig. 3b. From 5 to $0.002 \mathrm{hPa}$, the v4 MLS-v2.0 SABER bias profile in Fig. 5 is used to correct MLS temperatures, given evidence of large MLS cold biases at higher altitudes (Schwartz et al. 2008; French and Mulligan 2010; García-Comas et al. 2014).

The MLS and SABER contributions to the observation-error covariance matrix $\mathbf{R}$ are diagonal and assigned for each profile from source retrieval values.

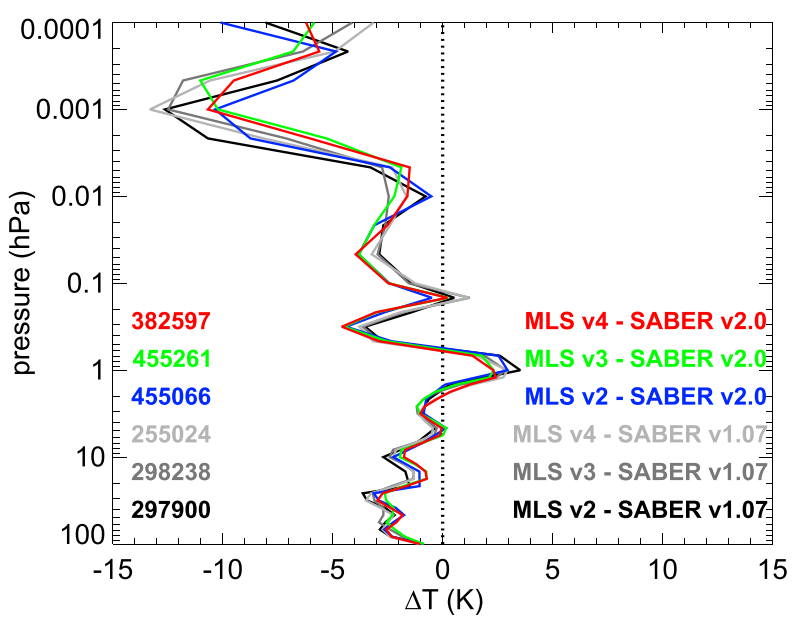

FIG. 5. Global-mean temperature biases between v2, v3, and v4 MLS and v1.07 and v2.0 SABER temperatures, based on coincidence criteria in local time of $\Delta t \leq 1 \mathrm{~h}$ and in horizontal location of $\Delta h \leq 200 \mathrm{~km}$. Number of coincidences is shown on left, based on data from 2005 to 2012 for v1.07 SABER, 2005-14 for v2.0 SABER and v2 and v3 MLS, and 2005-15 for v2.0 SABER and v4 MLS.

For both MLS and SABER, this error is set to a minimum floor value of $2 \mathrm{~K}$ at altitudes below $0.1 \mathrm{hPa}$, then scaled linearly in pressure height up to $4 \mathrm{~K}$ at $10^{-3} \mathrm{hPa}$, based on subjective fits to typical uncertainties documented in Schwartz et al. (2008) and Remsberg et al. (2008).

We also assimilate v4.2 MLS ozone retrievals from 100 to $0.6 \mathrm{hPa}$ and v4.2 MLS water vapor retrievals from 50 to $0.002 \mathrm{hPa}$. Since MLS water vapor precision degrades rapidly with height at upper levels [e.g., Table 2 of Lambert et al. (2007)], as in Eckermann et al. (2009), adjacent data are smoothed at heights above $0.05 \mathrm{hPa}$ by applying three-point along-track smoothing prior to assimilation. From 0.012 to $0.005 \mathrm{hPa}$, this along-track smoother is applied twice; from 0.005 to $0.003 \mathrm{hPa}$ it is applied three times; and from 0.003 to $0.002 \mathrm{hPa}$ it is applied four times.

\section{2) SSMIS UAS RADIANCES}

The Special Sensor Microwave Imager/Sounder (SSMIS; Kunkee et al. 2008) is a conical-scanning, nadir-viewing, 24-channel radiometer deployed on operational satellites of the Defense Meteorological Satellite Program (DMSP). With the launch of the DMSP F19 satellite on 3 April 2014, SSMIS radiances from four DMSP satellites $(F 16-F 19)$ were potentially available for assimilation during the 2014 austral winter. However, in April 2013, SSMIS temperature sounding channels on F16 suffered hardware failures of the $56.4-\mathrm{GHz}$ phase-locked oscillator (PLO) controlling precise 
TABLE 1. The four NAVGEM L74 DEEPWAVE reanalysis experiments.

\begin{tabular}{|c|c|c|c|c|c|}
\hline \multirow[b]{2}{*}{ Experiment name } & \multicolumn{2}{|c|}{ System resolution } & \multirow[b]{2}{*}{ DA algorithm } & \multirow[b]{2}{*}{ Start date (0000 UTC) } & \multirow[b]{2}{*}{ End date (0000 UTC) } \\
\hline & Outer loop & Inner loop & & & \\
\hline HYBRID119 & T119L74 & T47L74 & Hybrid 4DVAR & 20 Mar 2014 & 1 Jan 2015 \\
\hline 4DVAR119 & T119L74 & T47L74 & 4DVAR & 20 Mar 2014 & 1 Oct 2014 \\
\hline HYBRID425 & T425L74 & T119L74 & Hybrid 4DVAR & 20 Mar 2014 & 1 Oct 2014 \\
\hline 4DVAR425 & T425L74 & T119L74 & 4DVAR & 20 Mar 2014 & 1 Oct 2014 \\
\hline
\end{tabular}

positioning of central channel frequencies. A resulting failsafe PLO mode that attempts to regain frequency lock via continuous frequency sweeps allowed temperature information to be recovered only from the single passband lower-atmosphere sounding (LAS) temperature channels on F16 after April 2013.

Unless otherwise noted below, our assimilation of microwave radiances from the six SSMIS upper-atmosphere sounding (UAS) channels 19-24 (Swadley et al. 2008) on $F 17, F 18$, and $F 19$ follows procedures described in sections 3a and 4a of Hoppel et al. (2013). Since the SSMIS UAS channels have extremely narrow frequency bandwidths, additional spatial averaging is necessary to lower the effective scene noise required by NWP assimilation systems. Thus, unlike data from other satellite nadir sensors, which are averaged and thinned by the NAVGEM preprocessor (PP) and quality control (QC) algorithms, SSMIS radiance averaging is performed prior to transfer of the data to NAVGEM by onboard flight software and then by the SSMIS Unified Preprocessor (UPP; Bell et al. 2008). The original UPP has been modified to increase the spatial averaging of UAS radiances, as well as adding information necessary for the UAS-channel components of the Community Radiative Transfer Model (CRTM; Han et al. 2010), such as the upwelling radiation propagation vector and geomagnetic field vectors (Maurer et al. 2015). Within NAVGEM, systematic radiance biases are identified and removed using variational bias correction (varBC; Dee and Uppala 2009), with the LAS and UAS channels treated separately, replacing earlier SSMIS bias-correction procedures described in section 4a of Hoppel et al. (2013). Bias-corrected UAS radiances are assimilated here using version 2.2.1 of the CRTM that incorporates Zeeman splitting of $\mathrm{O}_{2}$ lines by geomagnetic fields and frequency shifts due to Earth's rotation. Prognostic temperature inputs to the CRTM are capped at $10^{-3} \mathrm{hPa}$ and replaced by climatology at higher levels.

As shown in Fig. 1 of Hoppel et al. (2013), SSMIS UAS radiances provide observational temperature information from $\sim 20$ - to $100-\mathrm{km}$ altitude, with LAS channels extending temperature coverage to the surface [see Fig. 3 of Kunkee et al. (2008)].

\section{0-100-km reanalyses for 2014 austral winter \\ a. Experiments}

As summarized in Table 1, we conducted four separate L74 NAVGEM reanalysis experiments.

Our control 4DVAR runs (hereafter labeled "4DVAR") deactivated the inner-loop ensemble capability such that background error covariances were specified statically $\left(\mathbf{P}_{0}^{b}=\mathbf{P}_{\text {static }}^{b}\right)$, equivalent to setting $\alpha=0$ in (15). This corresponds to a previous wellvalidated operational NAVGEM configuration (e.g., Campbell et al. 2017).

Our research reanalysis runs (hereafter labeled "HYBRID") sought to exploit new hybrid-4DVAR assimilation capabilities recently accommodated within NAVGEM that, as discussed in section $2 b(2)$, offer potentially large improvements in reanalysis skill in the MLT. While for purely MLT applications $\alpha=1$ in (15) is appealing, for DEEPWAVE science we require reanalysis skill at all altitudes. Kuhl et al. (2013) and Allen et al. (2018) documented significant improvements in tropospheric and stratospheric skill using $\alpha=0.5$, but diminished skill using $\alpha=1$. Thus, we adopted $\alpha=0.5$ for our HYBRID runs. Note that this is still a higher $\alpha$ value than the $\alpha=0.25$ adopted for the initial transition of a hybrid-4DVAR T425L60 NAVGEM to operations at FNMOC during 2017.

Both the 4DVAR and HYBRID experiments were performed at two different horizontal resolutions. "Synoptic" runs (hereafter denoted "119") adopted outer-loop triangular spectral truncation at total wavenumber 119 (T119) and used a full quadratic Gaussian grid within the forecast model, yielding grid cells of $\sim 1^{\circ} \times 1^{\circ}$ globally. The inner-loop resolution used for both the TLM and the 80-member forecast ensembles (see Fig. 2) was T47. These runs were designed to capture the large-scale atmospheric structure affecting gravity wave generation, deep propagation, and breakdown. "Gravity wave resolving" runs (hereafter denoted " 425 ") used the operational T425 outer-loop resolution and a reduced quadratic Gaussian grid (Hortal and Simmons 1991), yielding model grid cells at $\sim 45^{\circ} \mathrm{S}$ of $\sim 0.38^{\circ}$ in longitude and $\sim 0.28^{\circ}$ in latitude. 
These runs were designed to partially resolve gravity wave dynamics. Inner-loop resolution in this case was T119.

All four experiments were initialized from a previous reanalysis at 0000 UTC 20 March 2014, with the first $\sim 2$ weeks devoted to "spinup" such that reliable reanalyses were available starting 1 April, then run out until the end of September, with the HYBRID119 run continuing to the end of the year.

\section{b. Ensemble error covariances $\mathbf{P}_{\text {flow }}^{b}$}

Figures $4 \mathrm{c}$ and $4 \mathrm{~d}$ show zonal-mean standard deviations of temperature and horizontal wind perturbations, respectively, averaged over all HYBRID119 inner-loop (T47) ensemble forecasts during July 2014. Relative to corresponding static values in Figs. $4 \mathrm{a}$ and $4 \mathrm{~b}$, these errors in July 2014 were generally comparable in the stratosphere but larger in the MLT.

Covariances were formed relative to an observation point located over the South Island of New Zealand $\left(45^{\circ} \mathrm{S}, 170^{\circ} \mathrm{E}\right)$ and averaged over all ensemble forecasts in July. Vertical temperature correlations in Fig. $4 \mathrm{~g}$ show similar properties to the static values in Fig. 4e.

Solid and dotted lines in Fig. 4h show variation with height of mean correlation coefficients between zonal and meridional components, respectively, of geostrophic and rotational wind perturbations in both HYBRID119 and HYBRID425 inner-loop ensemble forecasts. Through the free troposphere and stratosphere up to $\sim 0.1 \mathrm{hPa}$, correlations are high $(\sim 0.7 \pm 0.2)$ and within the range of (but slightly below) the static $|\mu|=0.82$ at $45^{\circ} \mathrm{S}$ in Fig. 4f. At levels above $0.1 \mathrm{hPa}$, correlation values decrease precipitously, consistent with the anticipated progressive breakdown of largescale geostrophic balance and dominance of unbalanced divergent kinetic energy in the MLT (Koshyk et al. 1999; McLandress et al. 2006). Assuming this divergent kinetic energy is mostly due to upward-propagating gravity waves and tides, wave-induced vertical displacements should yield anticorrelated temperature and divergence perturbations. Dashed lines in Fig. 4h show an increase in temperature-divergence anticorrelation through the MLT that corresponds with the reduction in geostrophic-rotational wind correlations. There is also strong temperature-divergence anticorrelation in the lower stratosphere, where divergent kinetic energy is much weaker than rotational kinetic energy. The minimum in temperature-divergence correlation and maximum in geostrophic-rotational wind correlation near $0.1 \mathrm{hPa}$ may relate to strong planetary wave-breaking during July that dominated temperature variability and transport at these altitudes, as discussed in section 5 (see also Gisinger et al. 2017).

\section{c. Observational diagnostics}

Figure 6 presents a color-coded checkerboard summary of observations assimilated during the 4DVAR119 experiment every $6 \mathrm{~h}$ from 10 June to 11 July 2014. Although $\sim 100$ million raw observations are read in during every cycle, NAVGEM's PP, QC, and data-thinning algorithms reduce that number substantially. The mean numbers of assimilated observations over the month from various sensors are listed in ascending order on the left axis of Fig. 6, revealing, on average, a total of $\sim 3.3$ million assimilated observations per cycle.

The largest number of assimilated observations in Fig. 6 comes from hyperspectral infrared nadir sensorsInfrared Atmospheric Sounding Interferometers (IASIs) on the European $\mathrm{MetOp}-\mathrm{A}$ and $\mathrm{MetOp}$ - $\mathrm{B}$ satellites and Atmospheric Infrared Sounder (AIRS) on NASA's Aqua satellite. NAVGEM assimilated radiances from 51 IASI and 50 AIRS channels in the temperature-sensitive $\sim 15-\mu \mathrm{m} \mathrm{CO}_{2}$ band, as well as a smaller selection of channel radiances at $\sim 4.5-$ $8 \mu \mathrm{m}$ (Campbell et al. 2017). This subset of channels all peaks in the troposphere and lower stratosphere. Temperature information in the mid- and upper stratosphere comes mostly from microwave $\mathrm{O}_{2}$ nadir radiances acquired by Advanced Microwave Sounding Unit-A (AMSU-A) sensors on NOAA, MetOp, and NASA Aqua satellites, specifically channels 9-14, which peak at altitudes ranging from $\sim 90$ up to $\sim 2 \mathrm{hPa}$ (see Fig. 1 of Eckermann et al. 2007). Nadir microwave radiances from temperature-sensitive tropospheric and stratospheric channels are also assimilated as available from the SSMIS LAS channels and from the Advanced Technology Microwave Sounder (ATMS) on NASA's Suomi National Polar-Orbiting Partnership (NPP) satellite.

Our three sensors providing MLT observations, marked in red on the left and right of Fig. 6, provide $\sim 250000$ observations every cycle to the reanalysis with no temporal gaps in coverage, or $\sim 7 \%$ of the assimilated data volume in the troposphere and stratosphere. While these MLT numbers may appear relatively low, they substantially improve on those of previous research DAS experiments that have assimilated either no MLT observations (e.g., Polavarapu et al. 2005; Ren et al. 2008; Wang et al. 2012; Rienecker et al. 2011; Long et al. 2013) or limited MLS or SABER observations from earlier retrievals (e.g., Ren et al. 2011; Gelaro et al. 2017). In fact, 2014 might represent a peak in satellite MLT data coverage for assimilation for the foreseeable future, given that both MLS and SABER are near the end of their mission lifetimes without comparable replacements available, SSMIS UAS capabilities have since failed on both $F 18$ and $F 19$, and there will be no 


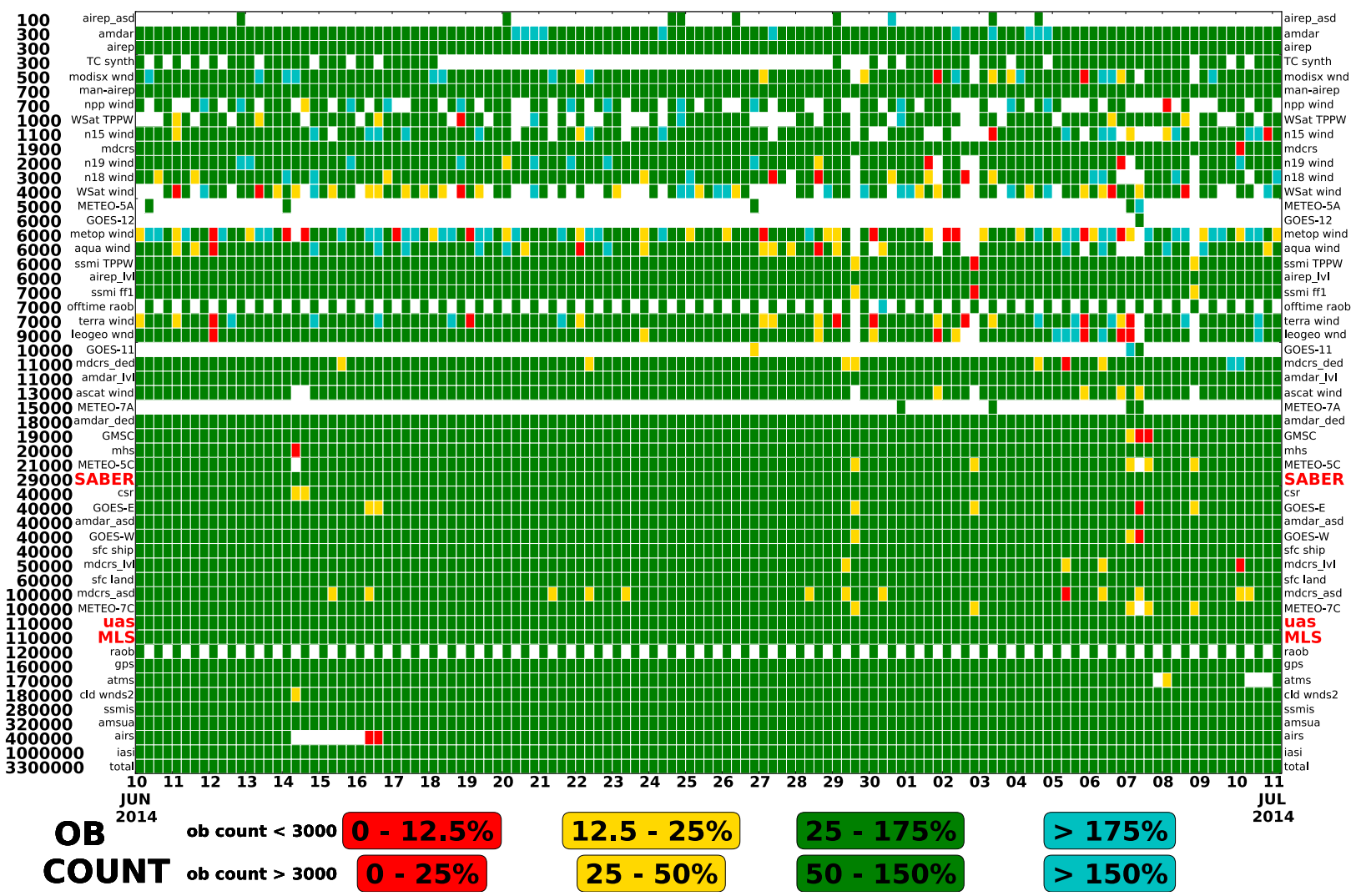

FIG. 6. Assimilated data counts for 4DVAR119 run every $6 \mathrm{~h}$ from $10 \mathrm{Jun}$ to $11 \mathrm{Jul} 2014$, listed by sensor and ordered vertically according to mean data counts over the month, for a mean total of $3.3 \times 10^{6}$ assimilated observations per cycle. Data sources used in operational NWP are listed using standard acronyms; see Table 1 of Hoover and Langland (2016). Color codes show instantaneous observation count as a percentage departure below or above sensor means (see color key at bottom; white indicates missing data). Note large data rates from the SABER and MLS sensors and SSMIS UAS channels (highlighted in red), which provide data above $\sim 50 \mathrm{~km}$, as well as from IASI, AIRS, AMSU-A, ATMS, and GPSRO sensors that provide data through the stratosphere up to $\sim 2 \mathrm{hPa}$. See text for additional details.

future SSMIS replacements with the recent cancellation of F20.

Figure 7 shows the global distribution of the major assimilated satellite observations for three consecutive NAVGEM update cycles during 1 July 2014. In the troposphere and stratosphere (bottom row), dense global pole-to-pole observational coverage is provided every cycle. In the MLT (top row), while observations are less dense, the combined coverage is also global. Just as important for MLT assimilation, nearly all longitudes are sampled at each latitude with few gaps in coverage, implying complete local time coverage in the MLT observations entering the analysis. This in turn allows the combined MLT observations to provide information on migrating and nonmigrating solar tides to the analysis. Note also that unlike the other sensors in Fig. 7, which are in polar orbits, TIMED orbits at a $74^{\circ}$ inclination and undergoes a yaw cycle every $\sim 60$ days that changes SABER's viewing geometry. In Figs. 7a-7c, SABER is in its north-viewing cycle, whereas later in July, a TIMED yaw switched it to a south-viewing geometry.

Our MLT observations in Figs. 7a-7c are a combination of nadir-scanned radiances with high horizontal resolution but poor vertical resolution (SSMIS UAS) and limb-scanned temperature profiles with poorer horizontal coverage but high vertical resolution (MLS and SABER). Figures $7 \mathrm{~d}-7 \mathrm{f}$ show only the coverage of assimilated data from nadir sensors of the troposphere and stratosphere. Figure 8 shows an example of the high vertical resolution profile data entering the tropospheric and stratospheric analysis from global positioning system radio occultation (GPSRO) data available operationally from GPS-enabled satellite platforms, as well as observations from the worldwide radiosonde network (RAOBs). Included within the RAOBs are dropsonde observations of opportunity from aircraft sorties (e.g., into hurricanes) made available via near-real-time transmission through WMO's Global 
1 July 20140600 UTC

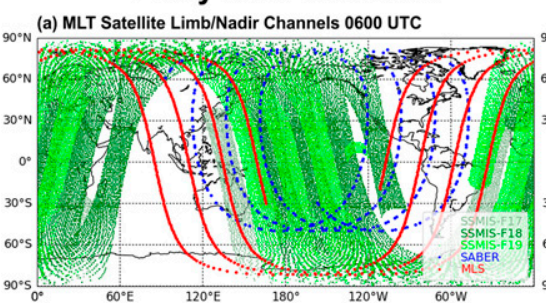

(d) Stratosphere-Troposphere Nadir Channels 0600 UTC

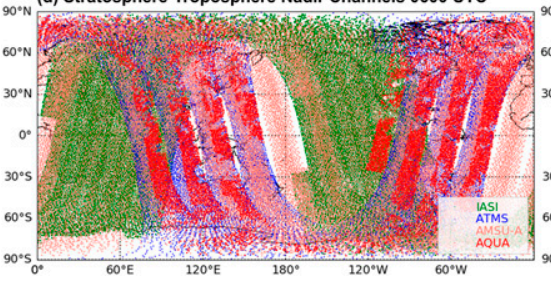

1 July 20141200 UTC (b) MLT Satellite Limb/Nadir Channels 1200 UTC

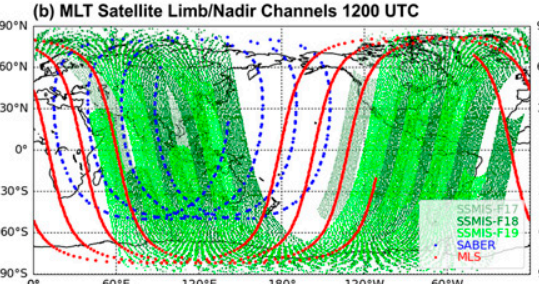

(e) Stratosphere-Troposphere Nadir Channels 1200 UTC

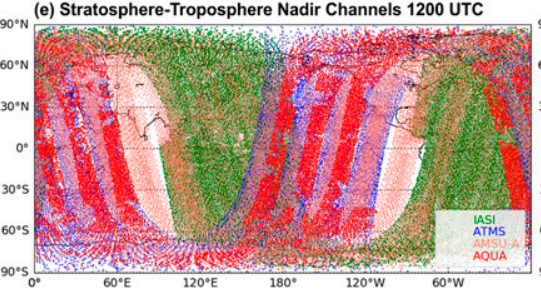

1 July 20141800 UTC
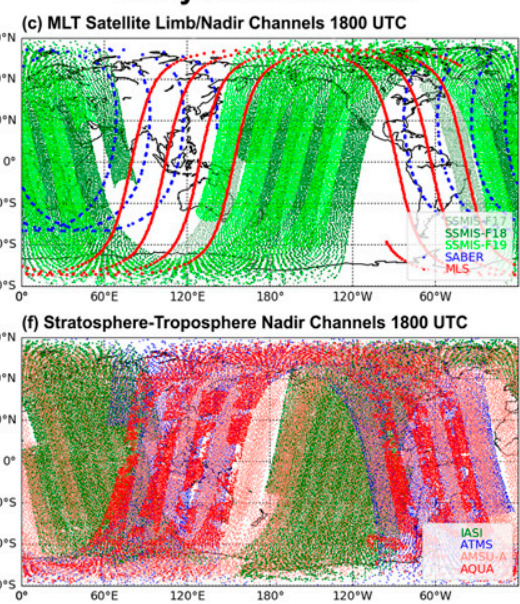

FIG. 7. Geographic sampling of observations assimilated within successive 6-h NAVGEM assimilation windows on 1 Jul 2014 centered at (a),(d) 0600; (b),(e) 1200; and (c),(f) 1800 UTC. (bottom) Sampling of satellite nadir radiances observed by IASI on $M e t O p$ - $A$ and $M e t O p-B$ (green), ATMS on Suomi NPP (blue), AMSU-A on Aqua, MetOp-A/B, NOAA-15-19 (pink), and AIRS and AMSU-A on Aqua (red). (top) Assimilated MLT observations from the SSMIS UAS channels on DMSP F17, F18, and F19 (green), SABER on TIMED (blue), and MLS on Aura (red).

Telecommunication System (GTS) to operational centers. These include AVAPS dropsonde data acquired from the NGV during DEEPWAVE (Fritts et al. 2016; Young et al. 2016); assimilated AVAPS profiles from DEEPWAVE research flight number 25 (RF25) are highlighted in black in Fig. 8.

Figure 9 shows an example of the bias-corrected SSMIS UAS radiance innovations provided as observational MLT inputs to NAVGEM. The plots show results for channels 19 and 21, which peak at $\sim 70-80$ - and $\sim 50-55-\mathrm{km}$ altitude, respectively, depending on local geomagnetic fields (Hoppel et al. 2013). These maps show that in addition to providing large-scale MLT temperature corrections, these horizontally dense innovations also provide information to the reanalysis about gravity waves in the MLT. In this case, the innovations reveal apparent large-amplitude orographic gravity wave structure above and downstream of the southern Andes. Intense stratospheric gravity waves at the same location with similar structure were confirmed by inspection of AIRS $15-\mu \mathrm{m}$ swath radiances used during DEEPWAVE (see Fritts et al. 2016). Given that the DA is performed at the inner-loop resolution and that $\mathbf{P}^{b}$ smooths observational corrections spatially via imposed vertical and horizontal correlations, the very finescale gravity wave structure evident in these

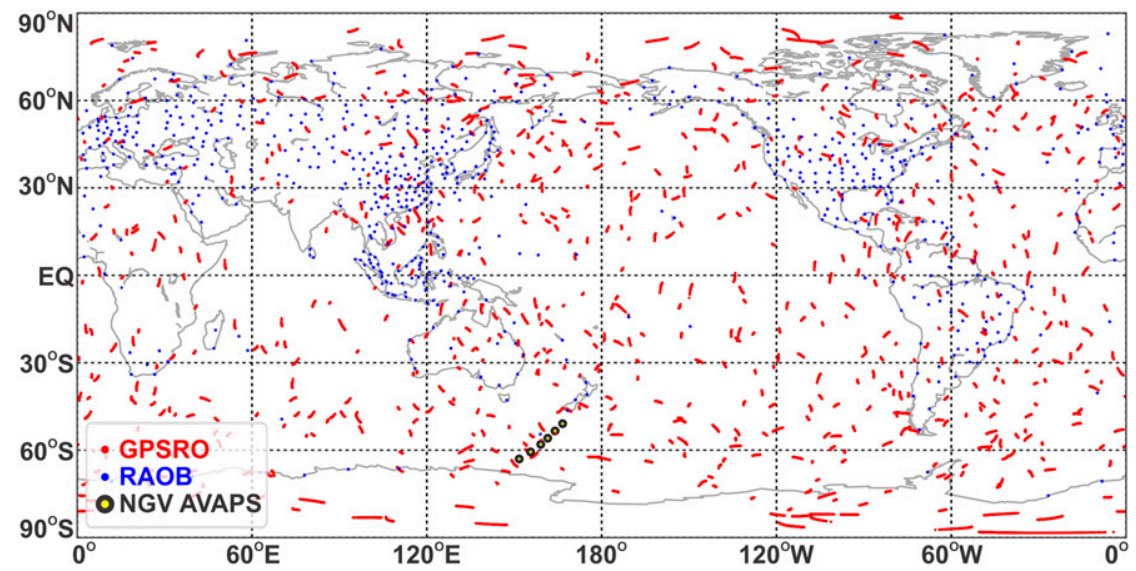

FIG. 8. Observational coverage during update cycle at 1200 UTC 18 Jul of GPSRO (red) and radiosonde/dropsonde observations (raob; blue). Assimilated NGV AVAPS observations from DEEPWAVE RF25 are highlighted with black/yellow circles. 
(a) F18 SSMIS-UAS Ch 19 Radiance Innovations: 14 June 20140000 UTC
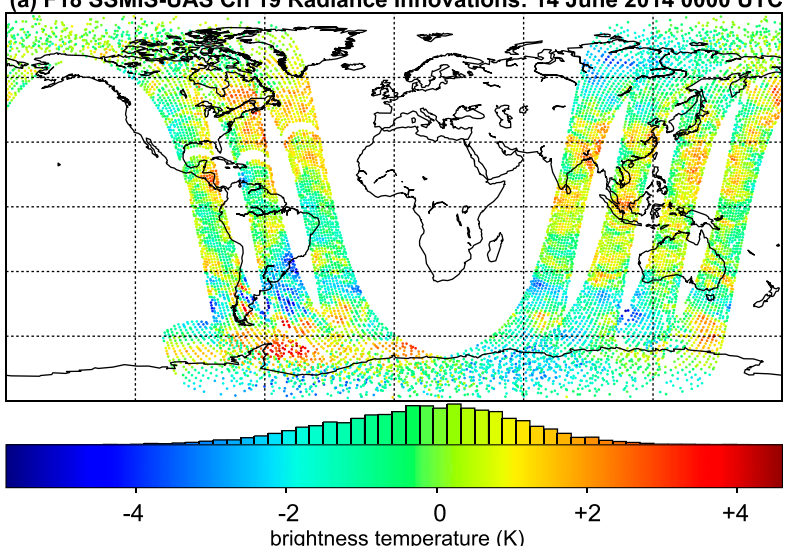

(b) F18 SSMIS-UAS Ch 21 Radiance Innovations: 14 June 20140000 UTC
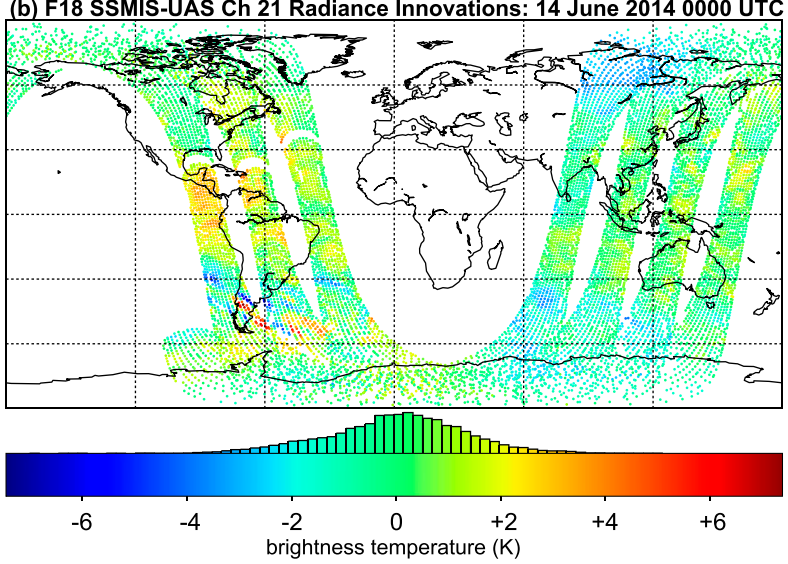

FIG. 9. NAVGEM HYBRID425 bias-corrected radiance innovations for F18 SSMIS UAS channels (a) 19 and (b) 21 at 0000 UTC 14 Jun 2014, expressed as a brightness temperature (K) Histograms on color bar show probability distribution of innovation values in each map.

innovation maps is probably not captured within MLT reanalysis increments.

\section{Observational validation of MLT reanalysis}

\section{a. MLT temperatures}

\section{1) SOFIE}

The Solar Occultation for Ice Experiment (SOFIE; Gordley et al. 2009) acquires $\sim 30$ high-latitude vertical profiles of MLT temperatures from NASA's Aeronomy of Ice in the Mesosphere (AIM) satellite each day. Although the restricted geographic and local-time coverage of these observations limits their potential impacts on reanalysis skill via direct assimilation, the high vertical resolution, precision, and accuracy of the limb temperature retrievals (Marshall et al. 2011) make SOFIE temperatures attractive as a high-quality independent validation standard for our MLT temperature reanalyses.

Figure 10a plots the geographic distribution of all the SOFIE temperature profiles acquired in the Southern Hemisphere from May to August 2014 (1624 in all). We interpolated NAVGEM reanalyses to the latitude, longitude, and time of each SOFIE limb profile, then interpolated SOFIE temperatures from the version 1.03 vertical retrieval grid (Marshall et al. 2011) onto the NAVGEM vertical model levels in Fig. 3. Figures 10b and $10 \mathrm{c}$ show resulting means and standard deviations, respectively, of temperature differences between SOFIE and each of the four NAVGEM MLT reanalyses.

Mean biases in Fig. 10b show a systematic NAVGEM 4DVAR warm bias that is absent from the HYBRID reanalyses. This MLT warm bias of 4DVAR relative to HYBRID is observed at other latitudes. The HYBRID MLT temperatures are unbiased to $\leqslant 1-2 \mathrm{~K}$ at all altitudes up to $\sim 10^{-3} \mathrm{hPa}$, above which a cold bias emerges. This cold bias may relate to errors near the heavily diffused NAVGEM upper boundary (see Fig. 3), but also to an apparent systematic warm bias in SOFIE temperatures relative to other observations above the mesopause (e.g., García-Comas et al. 2014).

Standard deviations of the temperature differences $\sigma_{T}$ increase with height in Fig. $10 \mathrm{c}$ from $\sim 6-7 \mathrm{~K}$ at $0.1 \mathrm{hPa}$ to $\sim 7-9 \mathrm{~K}$ at $0.01 \mathrm{hPa}$ and $\sim 12-15 \mathrm{~K}$ at $10^{-3} \mathrm{hPa}$. Nezlin et al. (2009b) showed a similar growth in $\sigma_{T}$ through the MLT due to growth in unpredictable error variance at high horizontal wavenumbers (see also Sankey et al. 2007; Liu et al. 2009). Consistent with high-wavenumber error growth, Fig. 10c reveals larger $\sigma_{T}$ in the T425 MLT reanalyses relative to T119. However, all $\sigma_{T}$ values in Fig. 10c are $20 \%-50 \%$ lower than the high-latitude winter MLT values reported by Nezlin et al. (2009b) in their assimilation experiments, despite their use of a T47 system. Since the Nezlin et al. (2009b) experiments assimilated no observations above $\sim 45-\mathrm{km}$ altitude, these findings are consistent with the MLT data denial experiments of Hoppel et al. (2013) that revealed up to $100 \%$ reductions in $\sigma_{T}$ at altitudes above $\sim 1 \mathrm{hPa}$ from assimilation of MLS, SABER, and SSMIS UAS observations relative to companion runs assimilating no MLT observations (see their Fig. 7).

These error variances also help to explain the warm bias of 4DVAR MLT reanalysis relative to HYBRID evident in Fig. 10b. The 4DVAR reanalysis adopts a $\mathbf{P}_{0}^{b}$ with $\alpha=0$ so that, as discussed in section $2 \mathrm{~b}(2)$, background error variances are specified statically via Eq. (13). Those static errors, plotted with a solid gray curve in Fig. 10c, become a progressively more serious underestimate of actual background errors $\sigma_{T}$ in the MLT, leading $4 \mathrm{DVAR}$ reanalyses to weight too strongly to 

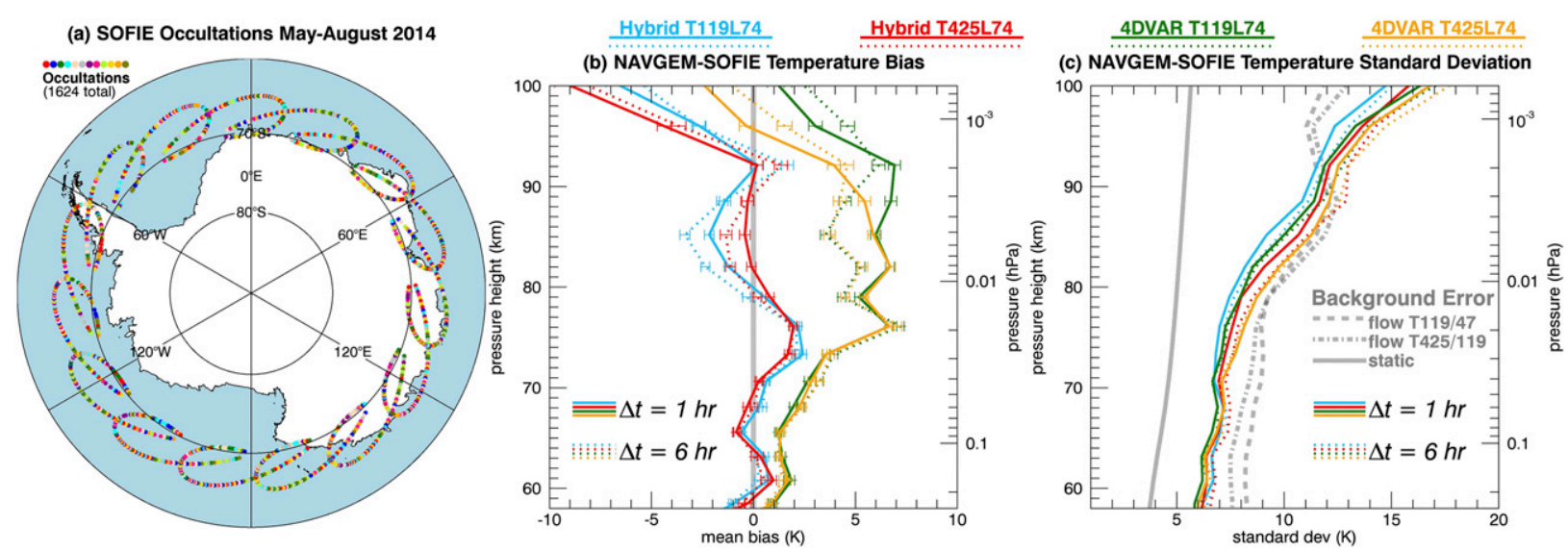

FIG. 10. (a) Geographic distribution of 1624 SOFIE solar limb occultation profiles acquired during May-August 2014. Colored curves in remaining panels show mean (b) bias and (c) standard deviation of temperatures from all four NAVGEM reanalyses (see color key at top) with respect to these SOFIE temperature profiles acquired at locations in (a). Error bars in (b) are standard errors of the mean derived from standard deviations in (c). Solid curves show results from 1-h NAVGEM fields, and dotted curves show results from 6-h analysis only. Gray curves in (c) show zonal-mean background errors at $67^{\circ} \mathrm{S}$ : zonal-mean static errors (solid curve; see Fig. 4a) and flow-dependent errors (broken curves) from the inner-loop ensemble forecasts in July 2014 for HYBRID119 (T47 inner; see Fig. 4c) and HYBRID425 (T119 inner).

MLT backgrounds over observations. This also suggests a systematic warm bias in the background MLT forecasts. By contrast, the HYBRID reanalysis with $\alpha=0.5$ incorporates the flow covariance $\mathbf{P}_{\text {flow }}^{b}$ calculated from 80 -member forecast ensembles in (14) into the $\mathbf{P}_{0}^{b}$ calculation in (15). These ensemble errors, shown with gray broken curves in Fig. 10c, capture the increases in MLT temperature errors evident in the SOFIE comparisons in Fig. 10c. Thus, HYBRID runs typically weight more to MLT observations than 4DVAR runs, given their greater and more realistic background temperature errors.

Dotted and solid curves in Figs. 10b and 10c compare results from interpolating NAVGEM fields at 6 - and 1-h time cadence, respectively. For HYBRID in particular, the addition of $+1-5$-h forecasts into the 6-h reanalysis stream improves reanalysis skill by reducing mean biases above $80 \mathrm{~km}$ and standard deviations above $60 \mathrm{~km}$. We show below that a major source of this improvement is through improved temporal resolution of MLT tidal temperature structure.

\section{2) DLR LIDAR}

The German Aerospace Center (DLR) deployed a Rayleigh-Raman lidar in Lauder, New Zealand $\left(45.04^{\circ} \mathrm{S}\right.$, $169.68^{\circ} \mathrm{E}$ ), that took measurements from 25 June to 3 November 2014. Kaifler et al. (2015) describe the instrument and data processing used to derive vertical temperature profiles extending into the MLT. Various temperature retrieval products were provided for DEEPWAVE with different space-time resolutions
(Kaifler and Kaifler 2016). Here, we use retrieved temperatures with an effective vertical resolution of $\sim 2.9 \mathrm{~km}$ and temporal resolution of $1 \mathrm{~h}$, since these data are a good match to the intrinsic height-time resolution of the NAVGEM reanalysis.

We first interpolated temperature reanalyses from full model levels onto an equispaced $1-\mathrm{km}$ grid of geometric heights $z$ above sea level spanning $0-110 \mathrm{~km}$, derived from reanalyzed geopotential heights $Z_{g}$ as $z=Z_{g} /\left(1-Z_{g} / a\right)$, where $a$ is mean Earth radius. We interpolated the NAVGEM reanalysis temperatures to the central measurement times of each individual lidar temperature profile acquired between 25 June and 30 September (1864 in all), then interpolated those lidar temperatures onto the 1-km NAVGEM $z$ grid.

Figures $11 \mathrm{a}$ and $11 \mathrm{~b}$ plot weighted means and standard deviations, respectively, of differences between the lidar and NAVGEM temperatures over Lauder. Weights were the inverse of the squared measurement error associated with each lidar temperature value; the gray curve in Fig. 11b shows the mean of those errors. From 30 to $50 \mathrm{~km}$, the biases of the NAVGEM HYBRID and 4DVAR reanalyses are all very similar and also compare closely to the bias of ECMWF operational analysis temperatures to these lidar data reported by Gisinger et al. (2017). Above $\sim 50 \mathrm{~km}$, the HYBRID and 4DVAR biases bifurcate, with the HYBRID reanalyses showing a small cold bias of $\sim 2 \mathrm{~K}$ up to $\sim 80 \mathrm{~km}$, while the 4DVAR reanalyses transition with height from no bias at $\sim 60 \mathrm{~km}$ to $\sim 2-\mathrm{K}$ warm bias 
Hybrid T119L74 Hybrid T425L74 4DVAR T119L74 4DVAR T425L74 (a) NAVGEM-Lidar Temperature Bias

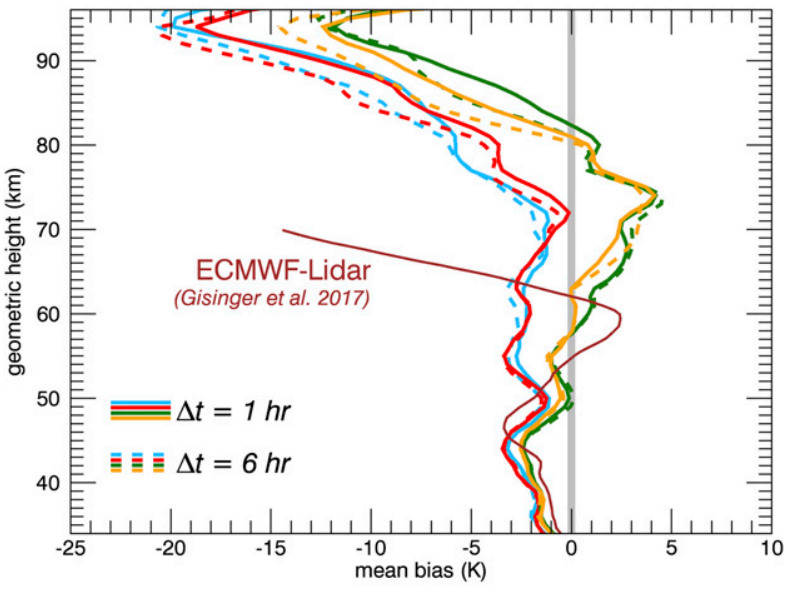

Hybrid T119L74 Hybrid T425L74 4DVAR T119L74 4DVAR T425L74

(b) NAVGEM-Lidar Temperature Standard Deviation

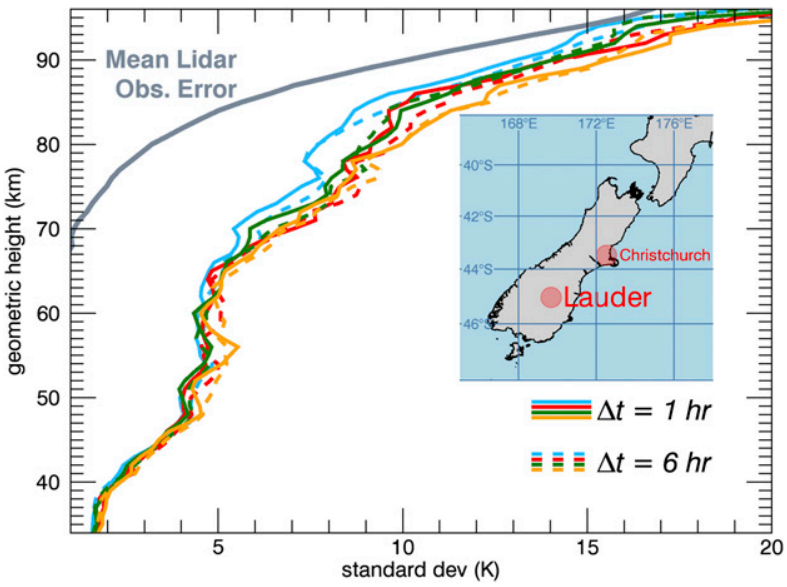

FIG. 11. (a) Mean temperature bias between NAVGEM reanalyses and DLR lidar profiles acquired from Lauder [see map inset in (b)] from 25 Jun to 30 Sep (1864 profiles in all). Color keys for each NAVGEM reanalysis are provided above each plot panel, with solid and dotted curves indicating use of analysis fields with 1- and 6-h resolution, respectively. Dark solid curve shows mean bias between lidar and ECMWF operational analysis temperatures from July to September 2014 [after Fig. B2 of Gisinger et al. (2017)]. (b) Corresponding error-weighted standard deviations between NAVGEM and DLR lidar profiles. Gray curve shows mean lidar measurement error.

at $\sim 75 \mathrm{~km}$. The 4DVAR bias tracks the bias in ECMWF up to $\sim 60 \mathrm{~km}$.

Above $\sim 80 \mathrm{~km}$, all the NAVGEM analyses exhibit an increasing cold bias with height, but with 4DVAR remaining systematically warmer than HYBRID. This may reflect errors in both NAVGEM and the lidar retrievals as both near their upper boundaries. It is interesting that at the upper boundaries of both NAVGEM at $z \sim 100 \mathrm{~km}$ and ECMWF at $z \sim 70 \mathrm{~km}$, large systematic vertical increases in cold bias appear in Fig. 11a.
To study local time variations over Lauder, we interpolated lidar and NAVGEM profile pairs from the irregular measurement times on each night onto a common regular local-time grid of 30-min resolution. We computed means within each time bin, then extracted the time-mean profile to study anomalies versus local time. Figure 12a plots the lidar temperature anomalies as a function of local time. The panel beneath it shows the total number of $1-\mathrm{km}$ layers from 30 to $100 \mathrm{~km}$ containing a lidar temperature measurement within each time interval, revealing fairly uniform measurement coverage from $\sim 0800$ to 1700 UTC (local time at Lauder is $12 \mathrm{~h}$ ahead of UTC). The mean lidar temperature anomalies reveal downward progression with local time of warm and cold anomalies, separated by $\sim 6 \mathrm{~h}$ and extending continuously from the stratosphere through the MLT, with mean amplitudes peaking at $\sim 7 \mathrm{~K}$ near $\sim 90 \mathrm{~km}$, though the exact peak altitude is complicated by measurement noise (see Fig. 11b). These local time variations reflect the mean temperature structure over Lauder of a large-amplitude migrating semidiurnal tide that was persistent in the MLT during DEEPWAVE (see section 5b).

Remaining panels in Fig. 12 show corresponding mean temperature anomalies over Lauder using the NAVGEM reanalyses. The top row shows results from the HYBRID119 reanalyses at different time cadences. At 1-h time cadence (Fig. 12b), there is excellent reproduction of the amplitude and phase of the observed temperature anomalies at all times and heights. Using a 3-h time cadence (analysis and $+3-\mathrm{h}$ background forecasts; Fig. 12c), there is still quite good agreement with the lidar data, although amplitudes are reduced. For a 6-h time cadence (Fig. 12d), the comparison is much poorer, most notably in the MLT where downward-propagating phase structure is lost, and local maxima and minima are both reduced and shifted in time. This aliasing problem highlights why the 6-h time cadence of analyses generated by standard forecast-assimilation update cycles at operational centers proves problematic when extending these systems through the MLT, given that, as in the DEEPWAVE region, MLT dynamics can often be dominated by large-amplitude semidiurnal tides.

Remaining panels on the bottom row of Fig. 12 show results from the other three reanalysis experiments at 1-h time cadence: 4DVAR119 (Fig. 12f), 4DVAR425 (Fig. 12g), and HYBRID425 (Fig. 12h). Again, the time-height amplitude and phase structure is captured well in the other reanalyses, although MLT amplitudes are somewhat weaker in the 4DVAR425 results. 

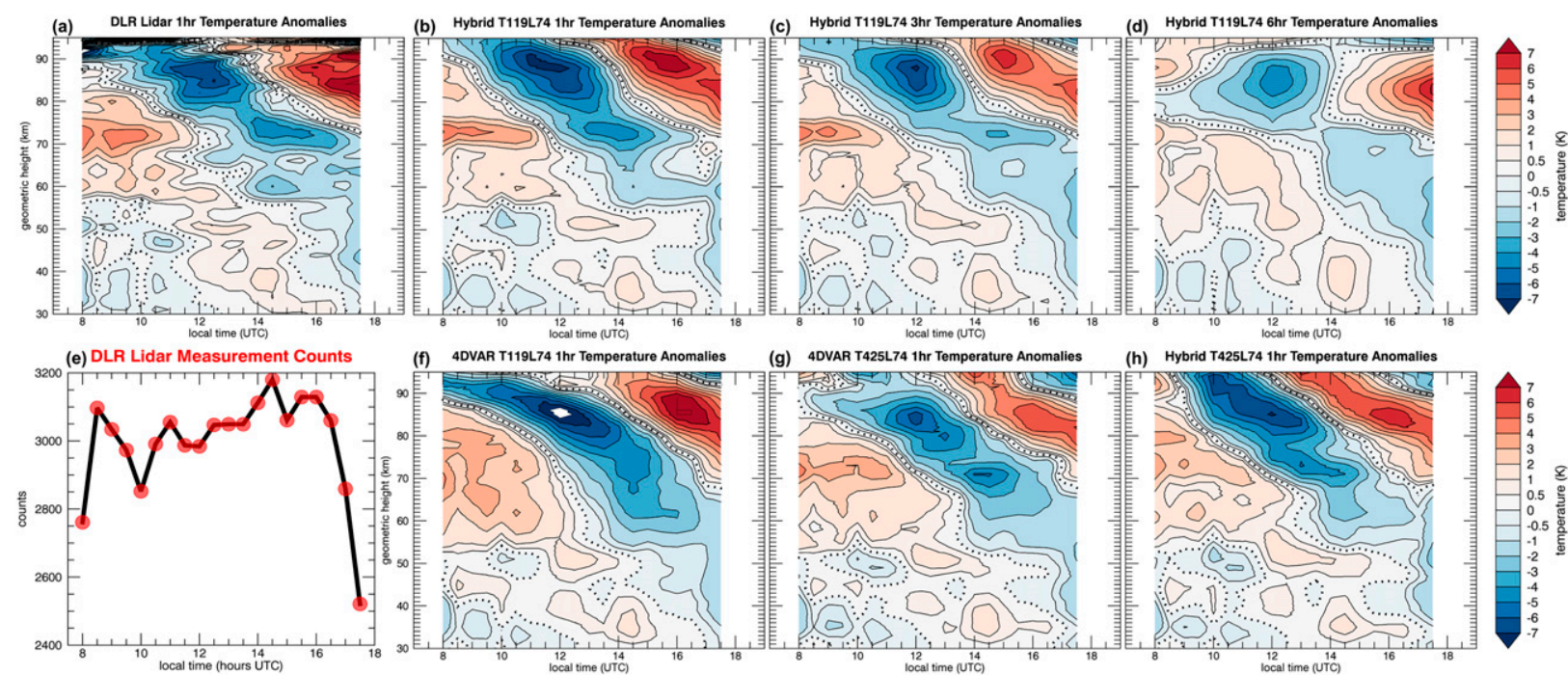

(g) 4 DVAR T425L74 $1 \mathrm{hr}$ Temperature Anomalies

(h) Hybrid T425L74 $1 \mathrm{hr}$ Temperature Anomalies

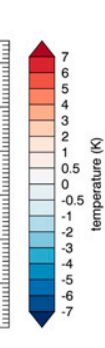

FIG. 12. (a) Mean lidar temperature anomalies vs UTC over Lauder (local time is $12 \mathrm{~h}$ ahead of UTC) based on averaging profiles from 25 Jun to 30 Sep 2014 and (e) total number of individual lidar temperature points in each 30-min time bin going into this mean. Remaining panels show corresponding results for NAVGEM reanalysis over Lauder: HYBRID119 at (b) 1-, (c) 3-, and (d) 6-h time cadence and 1-h reanalysis from (f) 4DVAR119, (g) 4DVAR425, and (h) HYBRID425. Note color bars on right for range and units.

\section{b. MLT winds}

The University of Adelaide and the Australian Antarctic Division deployed a portable meteor radar to measure MLT winds during DEEPWAVE. An "all sky" $55-\mathrm{MHz}$ antenna transmitted at a peak power of $40 \mathrm{~kW}$. Meteor echoes were received using a nearby five-antenna interferometer. Radial drift velocities of meteor ionization trails were derived from returned signals and used to derive wind velocities (see sections 2 and 3 of Holdsworth et al. 2004). As summarized in Fig. 13, the system was installed in Kingston, Tasmania, and observed winds in the MLT from $\sim 75$ to $100 \mathrm{~km}$ from mid-June through August 2014 (Reid et al. 2015).

To compare to the MLT winds observed hourly over Kingston, we reinterpolated 1-h NAVGEM reanalyses onto a 1-km geometric height grid then averaged MLT wind estimates at each height from 70 to $100 \mathrm{~km}$ within a $60-\mathrm{km}$ great circle radius over Kingston, as shown in Fig. 13a, to mimic all-sky meteor detection out to offzenith angles of $50^{\circ}-60^{\circ}$ [see Fig. 3 of Holdsworth et al. (2004)].

To separate and characterize mean and tidal effects in the MLT wind time series at each $z$, we performed least squares fits over a time window $L$ centered at some time $t_{c}$ to the harmonic function

$$
F(t)=a_{0}+\sum_{j=1}^{3} a_{j} \cos \left[2 \pi j\left(t / 24-b_{j}\right)\right]
$$

where $t$ is given in hours. The fitting interval $L$ was varied; here, we show results using $L=2$ and $L=$ 4 days. After each fit, $t_{c}$ was advanced by $1 \mathrm{~h}$ and the fitting repeated, thereby generating 1 -h time series at each altitude of mean wind $\left[a_{0}(z, t)\right]$, peak tidal wind amplitude, and tidal phase $\left[a_{j}(z, t), b_{j}(z, t)\right.$, $j=1, \ldots, 3]$. Zonal and meridional winds were fitted separately.

Black curves in Figs. 14a-14l show mean zonal (left column) and meridional (right column) meteor radar winds at $z=76-96 \mathrm{~km}$ from harmonic fits using $L=$ 2 days. Corresponding fits to the NAVGEM MLT reanalysis winds over Kingston are shown with colored curves. The figures reveal excellent reproduction of both the magnitude and variability of observed MLT winds in the reanalyses, although sporadic outliers are evident at times. For example, the 4DVAR zonal winds become excessively strong around day 60 (late July), whereas HYBRID reanalyses largely reproduce the radar observations at these times.

Mean biases with height are plotted in the bottom panels of Fig. 14. Results are shown using both the $L=$ 2-day fits and the original (unfitted) 1-h time series and show essentially the same properties. For zonal winds, the HYBRID reanalyses show good correspondences with radar winds below $90 \mathrm{~km}$, with mean MLT wind biases $\leqslant 5 \mathrm{~m} \mathrm{~s}^{-1}$, whereas the 4DVAR reanalyses show a more systematic eastward bias of up to $10 \mathrm{~m} \mathrm{~s}^{-1}$. Above $90 \mathrm{~km}$, all the analyses revert to an increasing westward bias that peaks near $-20 \mathrm{~m} \mathrm{~s}^{-1}$ at $\sim 100 \mathrm{~km}$. 


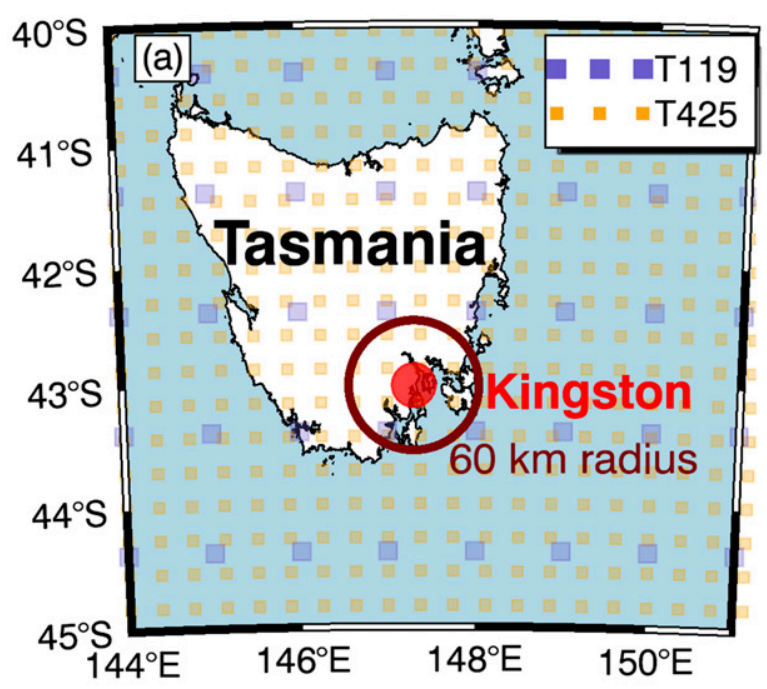

(c) Diurnal-Mean Meteor Counts
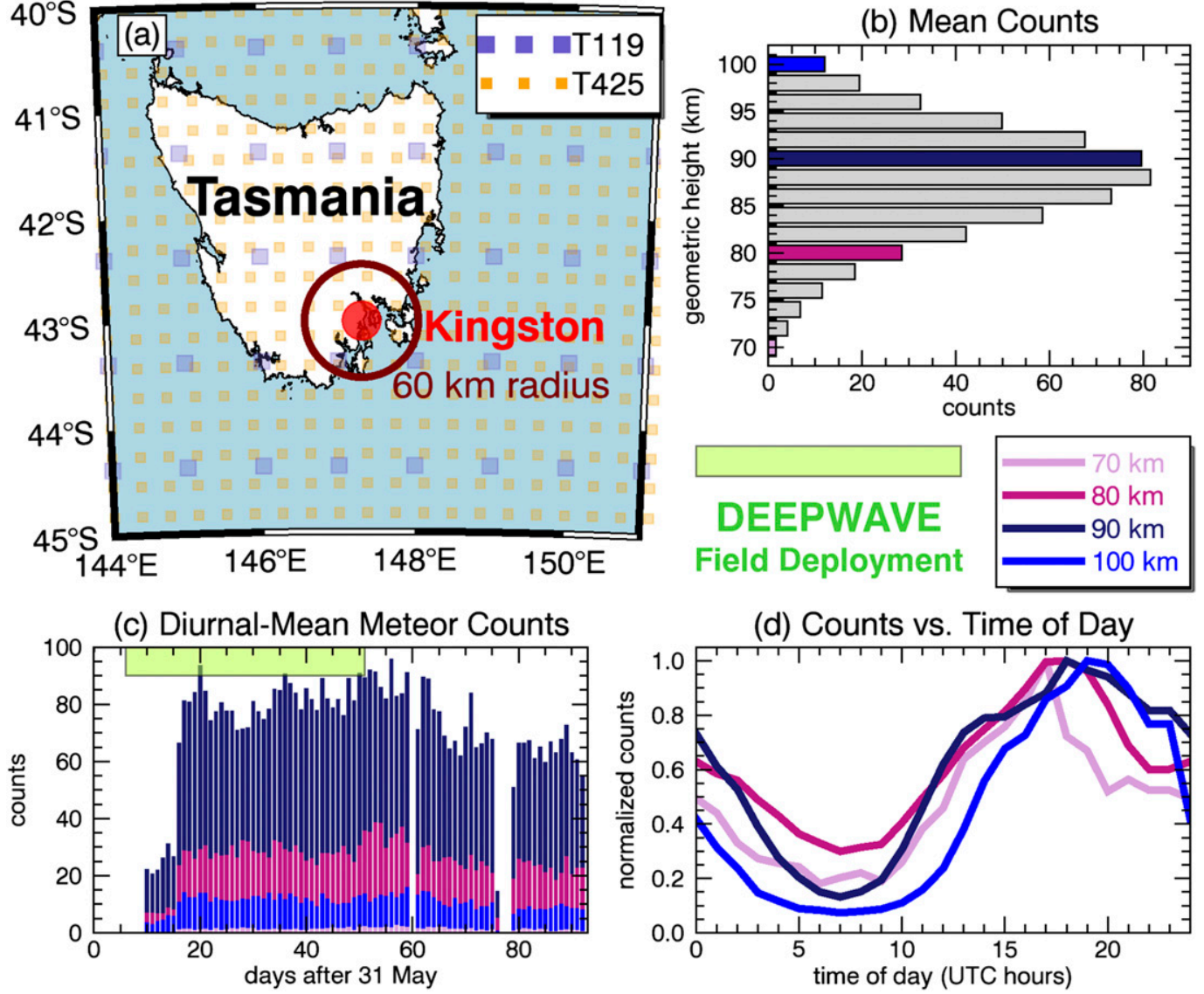

(d) Counts vs. Time of Day

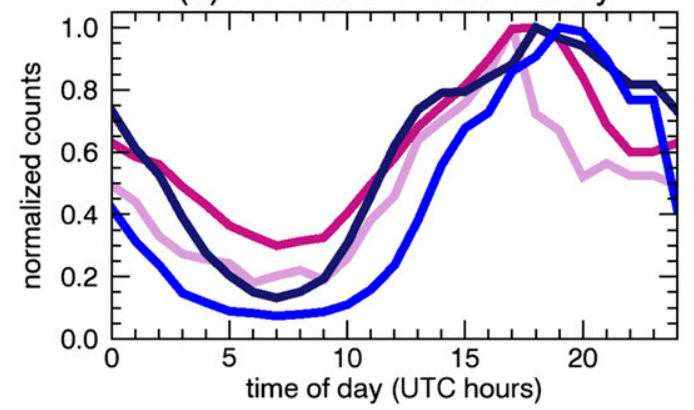

FIG. 13. (a) Location of Kingston meteor radar (red) and 60-km radius within which NAVGEM fields are averaged. Orange and purple squares show locations of model grid points at T119 and T425, respectively. Meteor wind counts are plotted as (b) means vs height, (c) diurnal means vs day number, and (d) normalized means vs time of day (local time is $+10 \mathrm{~h}$ ahead of UTC). Values at $70,80,90$, and $100 \mathrm{~km}$ are color coded in each panel. DEEPWAVE deployment period of 5 Jun-21 Jul is marked in green.

This upper-level westward bias may result from excessive parameterized NGWD in the uppermost levels of NAVGEM, since all remaining parameterized NGW flux is deposited in the uppermost two model layers (shown in orange in Fig. 3) to ensure robust prognostic downward-control circulations (see Eckermann 2011). Meridional winds likewise show small mean biases, but with more variability above $90 \mathrm{~km}$. Deviations below $\sim 75 \mathrm{~km}$ are due to low meteor counts (see Fig. 13b).

Corresponding standard deviations of the wind differences are plotted in Fig. 15. The results show that the HYBRID119 reanalysis substantially outperforms the other three reanalyses in reducing MLT wind errors. To test the robustness of this result, we performed an identical standard deviation calculation using meteor radar MLT winds from a second system at Buckland Park in southern Australia (Holdsworth et al. 2004; Reid et al. 2006). The results (not shown) were very similar to those over Kingston in Fig. 15, with HYBRID119 errors systematically smaller than those from the other analyses.

Reduced errors in the HYBRID119 run likely originate from the ensemble error covariance $\mathbf{P}_{\text {flow }}^{b}$ in (14) that more reliably maps MLT temperature-related innovations (e.g., Fig. 9) into realistic associated local MLT wind increments. Why the same benefit is not seen in HYBRID425 may relate to $\mathbf{P}_{\text {flow }}^{b}$ being affected negatively by unpredictable resolved gravity waves in the forecast ensembles near the truncation scale (Nezlin et al. 2009a), given the breakdown of geostrophic coupling and greater temperature-divergence coupling in the MLT noted in Fig. 4h, and an insufficient number of ensemble forecasts to remove any spurious net local correlations due to these unpredictable motions.

To assess this idea very preliminarily, we first recomputed standard deviations using reanalysis time series averaged within a $400-\mathrm{km}$ great circle radius over Kingston rather than $60 \mathrm{~km}$ (see Fig. 13a). The corresponding 

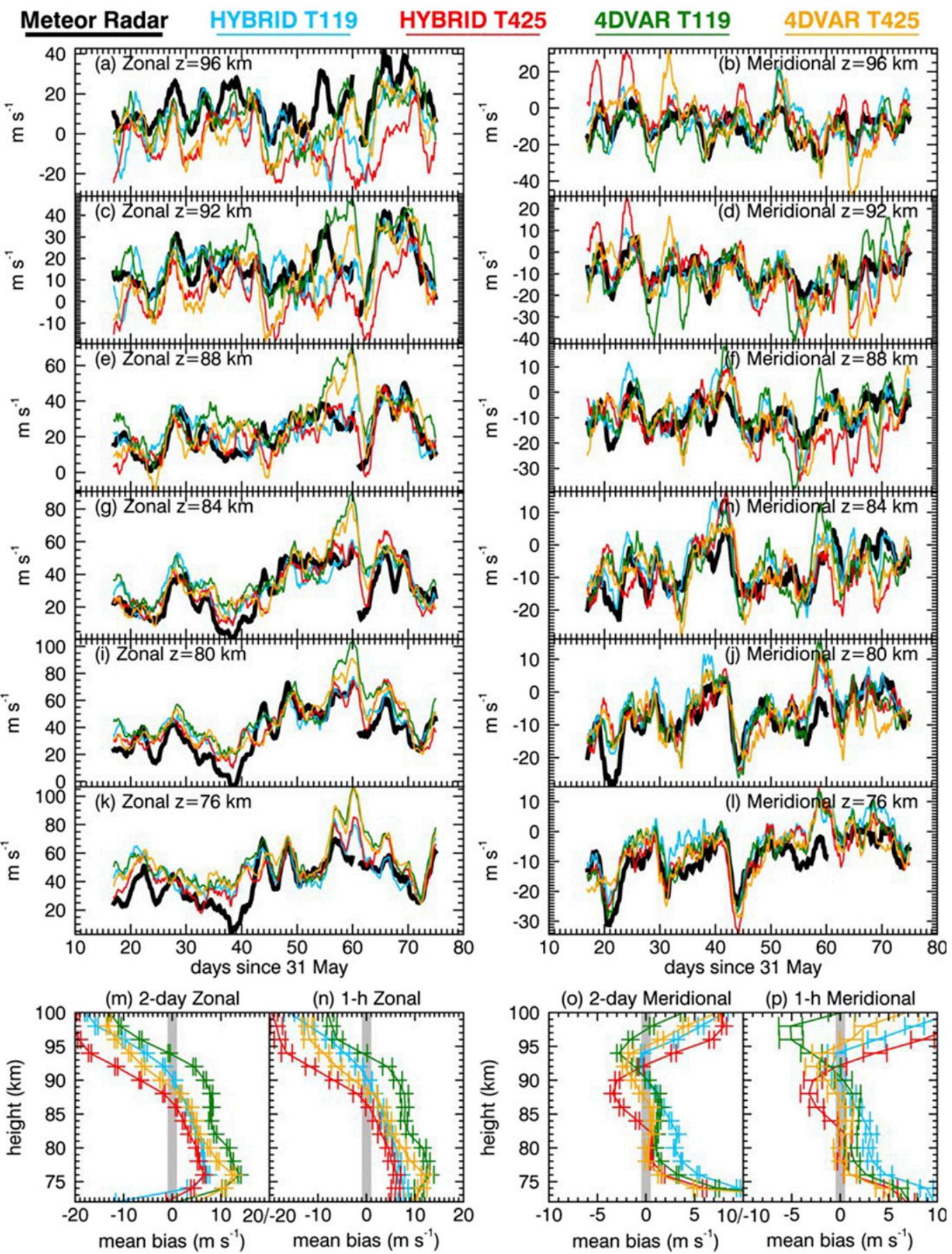

FIG. 14. Time series of mean zonal and meridional winds over Kingston at heights $z=76-96 \mathrm{~km}$ based on 2-day sliding harmonic fits; black curve shows meteor radar observations, and colored curves show NAVGEM reanalysis (see color key at top). (bottom) Mean biases between radar and reanalysis winds using the 2-day fits as well as the original (unfitted) 1-h time series. Error bars are standard errors of the mean.

plots (not shown) led to small but significant reductions in standard deviation such that HYBRID425 wind errors were less than 4 DVAR errors at all heights below $\sim 95 \mathrm{~km}$. Next, we performed a fifth NAVGEM reanalysis experiment that was identical to HYBRID119 but used an inner-loop resolution of T119 instead of T47. The resulting errors, plotted as pale blue curves in Fig. 15, were systematically larger than HYBRID119 
HYBRID T119 HYBRID T425 4DVAR T119 4DVAR T425 HYB 119/119

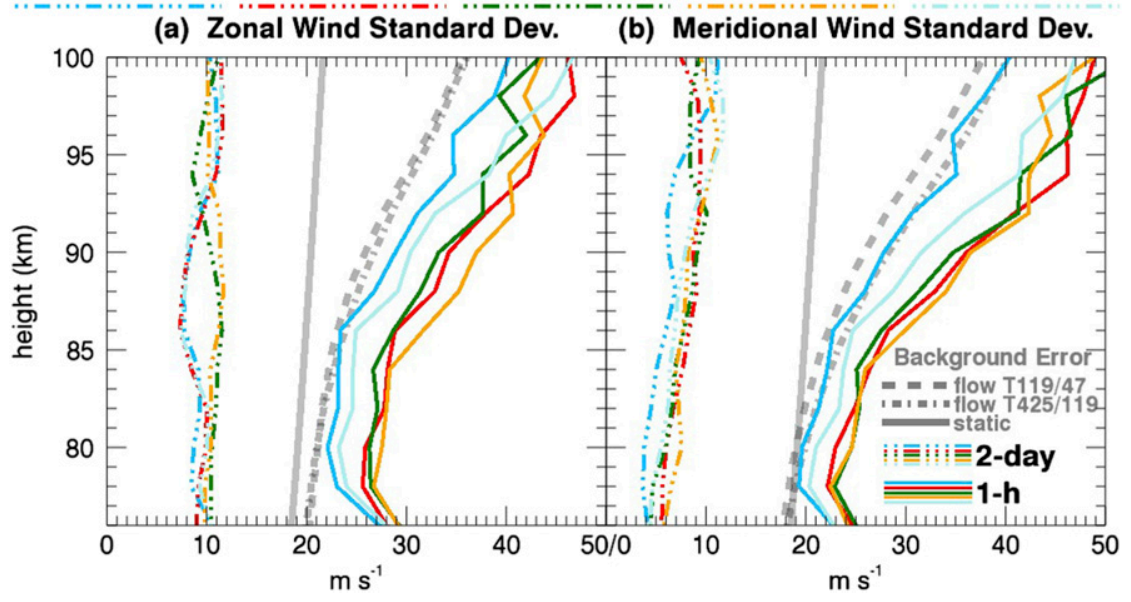

FIG. 15. Standard deviations of (a) zonal and (b) meridional wind differences between radar and reanalysis for 2-day harmonic fits (broken colored curves) and original (unfitted) 1-h fields (solid colored curves). Gray lines show zonal-mean static and flow-dependent background wind errors in NAVGEM at $43^{\circ} \mathrm{S}$ for July 2014.

but systematically smaller than HYBRID425 in the MLT. This result suggests that analysis errors may originate from unpredictable MLT variance near the truncation scale in both the inner-loop ensemble forecasts and the outer-loop background trajectory. More detailed study of this issue is warranted based on these initial findings.

\section{Planetary-scale MLT dynamics}

The 0-100-km NAVGEM reanalyses are used here to provide insights into planetary-scale dynamics of the MLT relevant to DEEPWAVE science. Our focus here is mostly on winds, given their primacy in controlling gravity wave propagation and breakdown through the MLT, and on the region in and around New Zealand where the core DEEPWAVE observations were acquired.

\section{a. Split stratopause jet in July}

Figure 16 profiles monthly mean zonal winds at latitudes $\left(20^{\circ}-70^{\circ} \mathrm{S}\right)$ and longitudes $\left(140^{\circ}-190^{\circ} \mathrm{E}\right)$ in and around New Zealand during June (top row) and July (bottom row).

Left panels show climatological zonal winds averaged from $140^{\circ}$ to $190^{\circ} \mathrm{E}$ using 20 years of reanalysis (19982017) from the Modern-Era Retrospective Analysis for Research and Applications version 2 (MERRA2; Gelaro et al. 2017). The July climatological means in Fig. $16 \mathrm{f}$ resemble the 3-yr high-altitude reanalysis means in Fig. 1a. Adjacent panels to the right show the corresponding $140^{\circ}-190^{\circ} \mathrm{E}$ MERRA2 zonal winds in 2014.
These plots show a stratopause jet over the DEEPWAVE area that was stronger than climatology during June 2014, then split into two separated stratospheric jets in July 2014. However, since both of these features occur near the 0.1-hPa upper boundary of the MERRA2 reanalysis, it is difficult to assess the reliability of these wind features or how they might evolve into the MLT to affect propagation and filtering of gravity waves observed during DEEPWAVE.

Figures $16 \mathrm{c}$ and $16 \mathrm{~h}$ show the corresponding zonal winds in 2014 from the NAVGEM HYBRID119 reanalysis. At altitudes below $0.1 \mathrm{hPa}$, the NAVGEM winds agree closely with MERRA2. However, only the NAVGEM reanalysis fully resolves the jet structure, revealing in Fig. 16c a stratopause jet peaking near $140 \mathrm{~m} \mathrm{~s}^{-1}$ at $\sim 0.1 \mathrm{hPa}$ just equatorward of Christchurch in June 2014. In July (Fig. 16h), this jet weakened to $\sim 90 \mathrm{~m} \mathrm{~s}^{-1}$ and ascended slightly, while a second stratospheric jet with similar peak wind speeds formed near $60^{\circ} \mathrm{S}$ and $\sim 5 \mathrm{hPa}$. Figure 16i shows that this split jet structure is not evident in the zonal means and, thus, is a dynamical feature unique to the DEEPWAVE geographic zone near New Zealand during July 2014. Panels on the far right of Fig. 16 show these local wind anomalies, revealing zonal winds at $1 \mathrm{hPa}$ near Christchurch that were $\sim 30 \mathrm{~m} \mathrm{~s}^{-1}$ weaker than zonal-mean values during July 2014.

Corresponding longitude-height cross-sections of local anomalies from the zonal mean are shown in Fig. 17, as computed from NAVGEM HYBRID119 and MERRA2 reanalyses within a $5^{\circ}$ latitude belt centered over Christchurch; the longitude of Christchurch is 

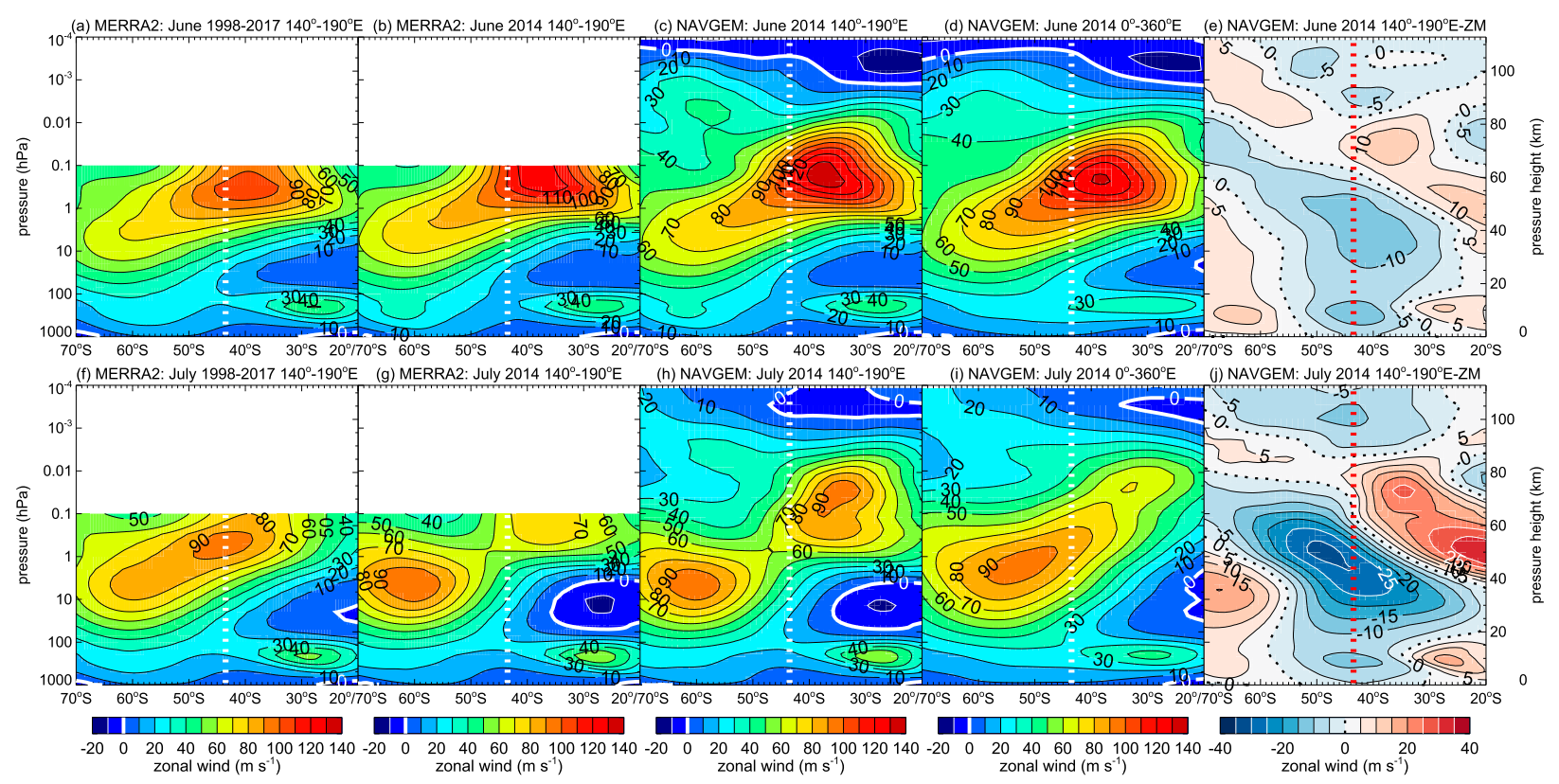

FIG. 16. Latitude-pressure cross sections of reanalysis zonal winds $\left(\mathrm{m} \mathrm{s}^{-1}\right.$; see underlying color bars) averaged over months of (top) June and (bottom) July. (a),(f) MERRA2 averaged from 1998 to 2017 within a DEEPWAVE zone from $140^{\circ}$ to $190^{\circ} \mathrm{E}$; (b),(g) MERRA2 for 2014 averaged from $140^{\circ}$ to $190^{\circ} \mathrm{E}$; (c),(h) NAVGEM HYBRID119 for 2014 averaged from $140^{\circ}$ to $190^{\circ} \mathrm{E}$; (d),(i) NAVGEM HYBRID119 for 2014 averaged from $0^{\circ}$ to $360^{\circ}$; and (e),(j) NAVGEM HYBRID119 zonal wind anomalies at $140^{\circ}-190^{\circ} \mathrm{E}$ relative to zonalmean (difference of adjacent two panels to left). Region above Christchurch is shown by dashed vertical line in each panel.

shown by the red dotted line. The plots reveal that this characteristic monthly mean anomaly structure originates from quasi-stationary wave- 1 Rossby wave dynamics. Top panels show monthly mean zonal-wind and geopotential-height anomalies in July 2014 from the HYBRID119 reanalysis, with the corresponding 20-yr mean anomalies from MERRA2 shown in panels beneath (middle row). All four panels reveal a sloping wave-1 pattern with similar phasing, but with the amplitudes in NAVGEM during July 2014 enhanced by factors of $\sim 3-4$ relative to the 20-yr MERRA2 climatology. Wave-1 geopotential-height amplitudes grow with height to a peak of $\sim 600-800 \mathrm{~m}$ at $\sim 1 \mathrm{hPa}$, in good agreement with mean amplitudes for July 2014 derived independently from MLS temperatures and from ECMWF analysis by Gisinger et al. (2017). Thus, the split-jet structure in Fig. 16h resulted from large-amplitude, quasi-stationary, wave-1 Rossby wave activity in the stratosphere during July.

The corresponding wave-1-induced anomalies in meridional wind and temperature are plotted in the bottom panels of Fig. 17. Figure $17 \mathrm{e}$ shows that stratospheric wave- 1 activity produced anomalous equatorward transport at $\sim 1-10 \mathrm{hPa}$ near Christchurch during July 2014, with peak meridional wind anomalies of $\sim 30 \mathrm{~m} \mathrm{~s}^{-1}$. This anomalous equatorward advection of cold polar stratospheric air yielded temperature anomalies at $1-10 \mathrm{hPa}$ as low as $-20 \mathrm{~K}$ above Christchurch in Fig. 17f.

The NAVGEM anomalies in Fig. 17 reveal that wave- 1 amplitudes attenuated significantly with height above $\sim 1 \mathrm{hPa}$. Planetary-wave Eliassen-Palm (EP) fluxes computed by Gisinger et al. (2017) confirm strong EP-flux divergence at altitudes above $\sim 40 \mathrm{~km}$ during July 2014, which drove the weakening of the zonal-mean stratopause jet evident in Fig. 16i and a zonal-mean warming in July 2014 relative to climatology peaking at $\sim 7 \mathrm{~K}$ at $1-10 \mathrm{hPa}$. Inspection of zonal-wind anomalies in Fig. 17a shows that wave-1 amplitudes essentially vanish at $0.01 \mathrm{hPa}(Z \sim 80 \mathrm{~km})$, but then reappear above $80 \mathrm{~km}$ and grow in amplitude into the MLT. These growing wave- 1 zonal-wind anomalies in the MLT are antiphased with the underlying wave- 1 structures in the upper stratosphere.

To study this wave-1 MLT feature in more depth, Fig. 18 shows maps of the mean wave- 1 anomalies in HYBRID119 reanalysis at a representative stratospheric level of $1 \mathrm{hPa}$ and an MLT level of $7 \times 10^{-3} \mathrm{hPa}$. The wave- 1 anomalies in zonal wind and geopotential height in the MLT have a very similar meridional structure to the large-amplitude wave-1 Rossby wave in the stratosphere, but are $\sim 180^{\circ}$ out of phase. Since this stratospheric wave-1 Rossby wave breaks below the MLT (Gisinger et al. 2017), we suggest that 
(a) NAVGEM: July $201446^{\circ}-41^{\circ} \mathrm{S}$

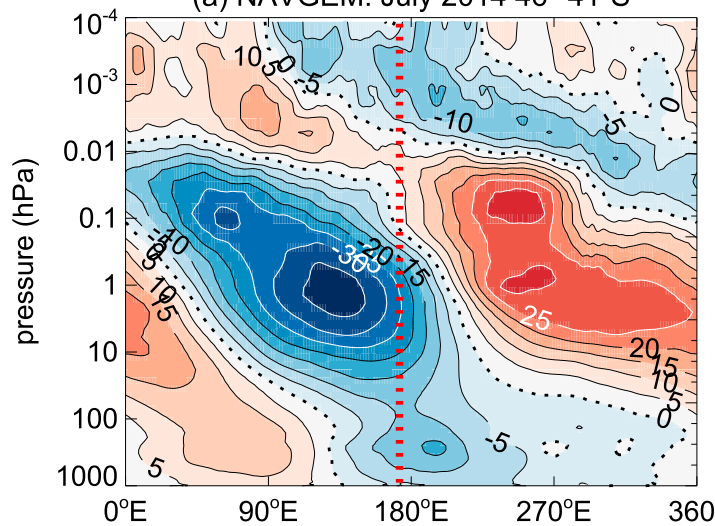

(c) MERRA2: July $1998-201746^{\circ}-41^{\circ} \mathrm{S}$

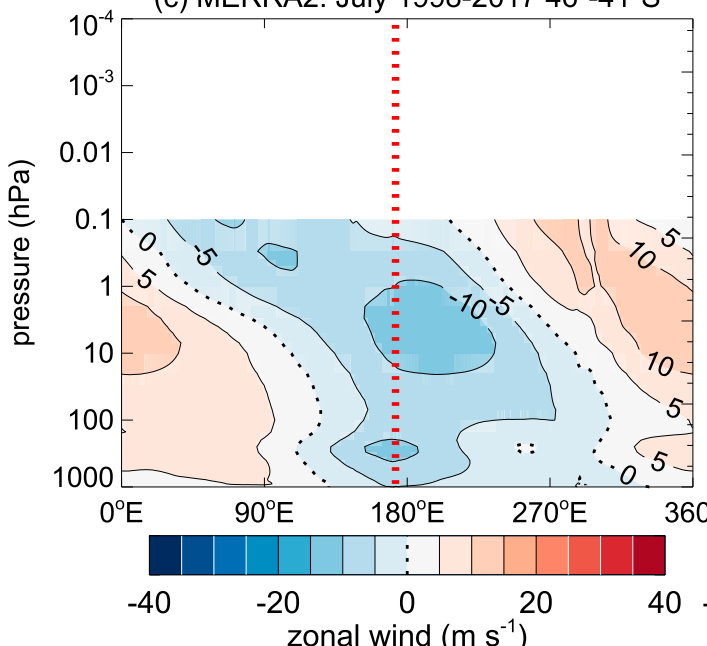

(e) NAVGEM: July $201446^{\circ}-41^{\circ} \mathrm{S}$

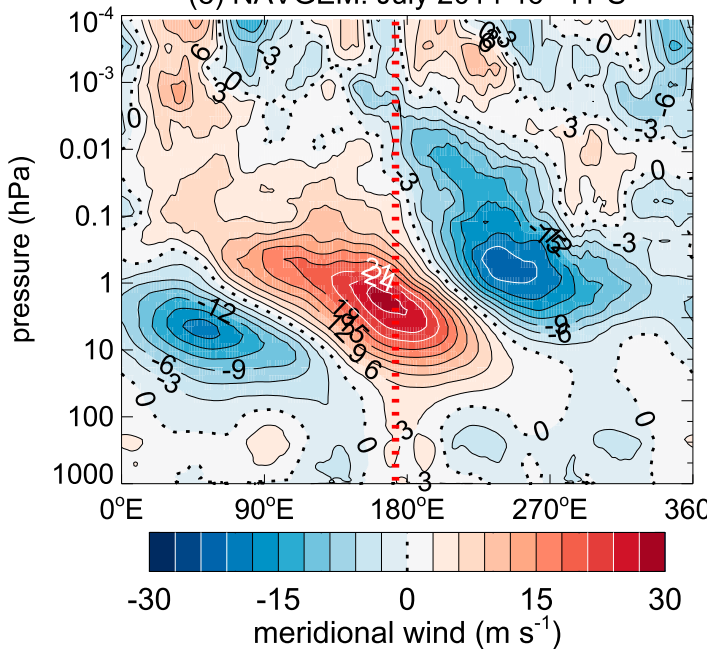

(b) NAVGEM: July $201446^{\circ}-41^{\circ} \mathrm{S}$

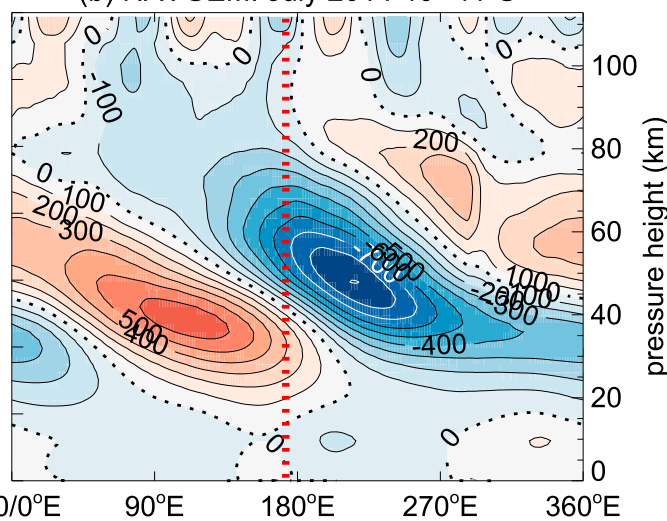

(d) MERRA2: July $1998-201746^{\circ}-41^{\circ} \mathrm{S}$

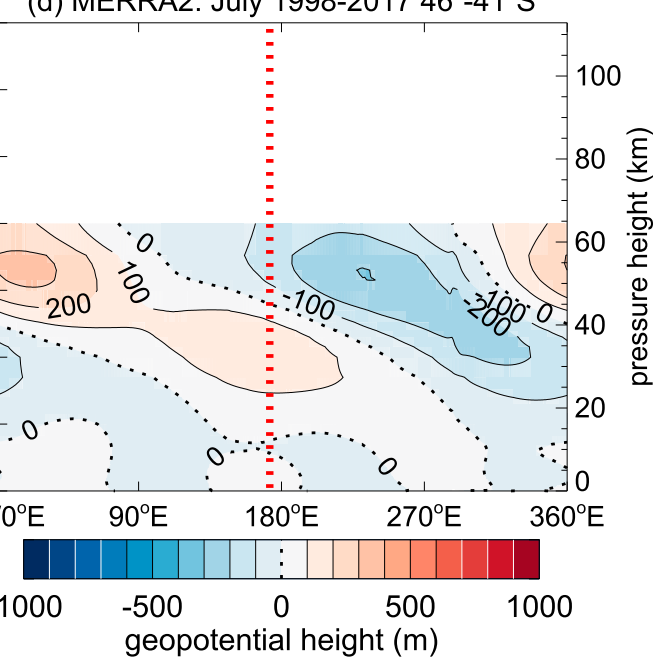

(f) NAVGEM: July $201446^{\circ}-41^{\circ} \mathrm{S}$

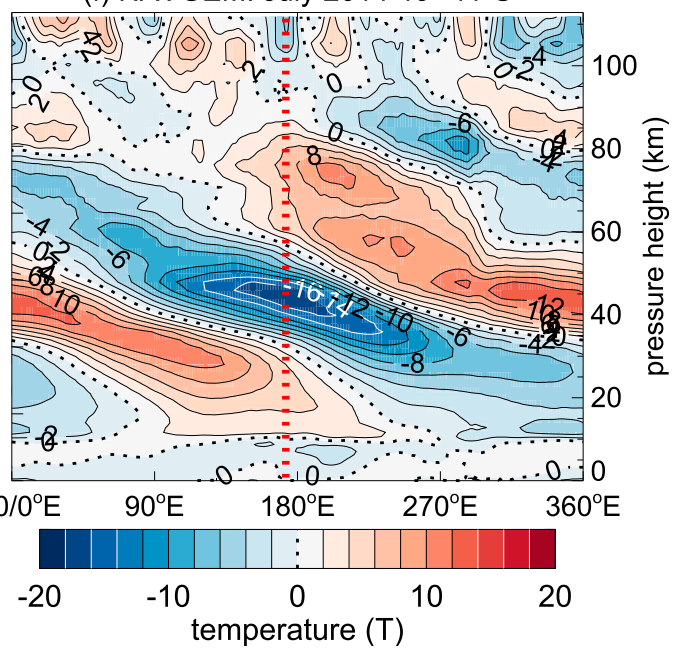

FIG. 17. Longitude-pressure cross sections of NAVGEM HYBRID119 anomalies (deviations from zonal mean) averaged from $41^{\circ}$ to $46^{\circ} \mathrm{S}$ for (a) zonal wind and (b) geopotential height in July 2014, with (c),(d) corresponding mean July anomalies for years 1998-2017 from MERRA2. (bottom) Corresponding HYBRID119 anomalies for July 2014 in (e) meridional wind and (f) temperature. Region above Christchurch is shown by dashed vertical red line in each panel. 

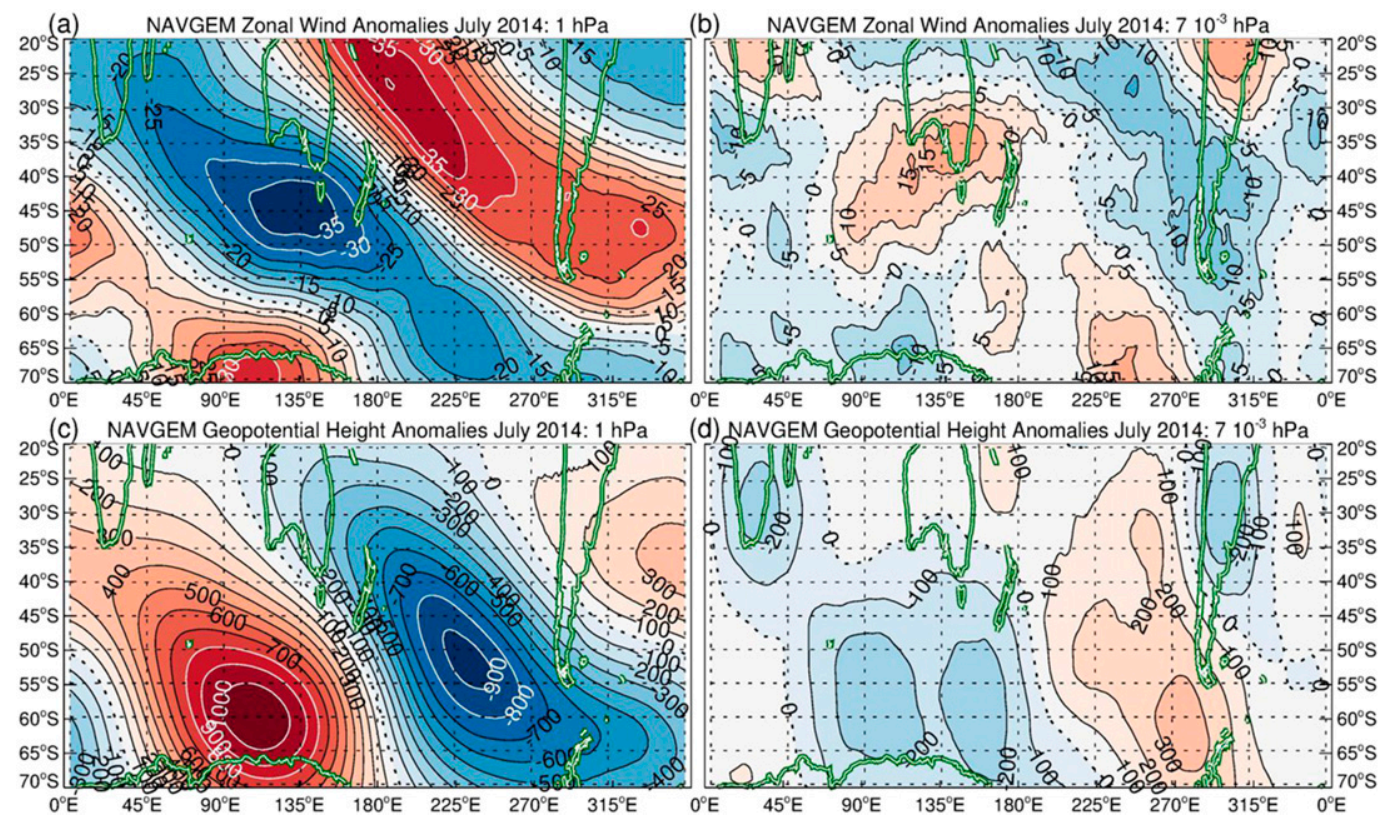

FIG. 18. Mean zonal-wind anomalies (departures from zonal mean) for July 2014 in the midlatitude Southern Hemisphere $\left(20^{\circ}-70^{\circ} \mathrm{S}\right)$, mapped at (a) a stratospheric pressure level of $1 \mathrm{hPa}$ and (b) an MLT pressure level of $7 \times$ $10^{-3} \mathrm{hPa}$, from the NAVGEM HYBRID119 reanalysis (contour labels in $\mathrm{m} \mathrm{s}^{-1}$ ). (c), (d) Corresponding results for geopotential height (contour labels in meters). Coastlines are plotted in green.

reemergence of this antiphased wave-1 anomaly structure in the MLT results from in situ MLT forcing. A plausible source of quasi-stationary wave-1 forcing in the MLT is zonally asymmetric GWD, resulting from zonal variations in stratospheric gravity wave filtering due to the zonally varying stratospheric zonal winds associated with the large-amplitude Rossby wave in Fig. 17a (e.g., Smith 2003).

\section{b. Large-amplitude semidiurnal tide}

Our earlier intercomparison of NAVGEM reanalysis with DLR lidar temperatures in the MLT (see Fig. 12) and some previous studies (e.g., Eckermann et al. 2016; Gisinger et al. 2017) suggested appreciable semidiurnal variation of the MLT during DEEPWAVE.

To investigate further, we computed two-dimensional space-time spectra from longitude-time (Hovmöller) cross sections of NAVGEM MLT reanalysis fields at a given latitude and height. Reanalysis fields were remapped onto a common geometric height and longitude grid, means removed, and two-dimensional power spectral densities (PSDs) formed and averaged within $5^{\circ}$ latitude belts equatorward and poleward of the South Island for June and July. The resulting mean space-time PSDs of horizontal MLT winds for June and July are plotted in Fig. 19 at $z=74 \mathrm{~km}$, to characterize nonstationary planetary-wave activity impinging on the MLT from below, and at $z=90 \mathrm{~km}$, to characterize the same planetary-wave activity deep within the MLT. Zonal wavenumbers are separated into components propagating westward (negative) and eastward (positive) using standard two-dimensional Fourier methods. The white line in each panel at westward wavenumbers depicts modes that migrate with the sun, upon which migrating solar tidal modes all lie.

While these spectra show evidence of weak migrating diurnal and terdiurnal tides, nonmigrating tidal modes, and (at $z=74 \mathrm{~km}$ ) fast eastward planetary-wave structure, all are dominated by a large-amplitude migrating semidiurnal tidal peak. The PSD value of this semidiurnal westward-propagating wave-2 (SW2) peak is displayed in each panel and in most cases (i.e., where the peak is colored red) exceeds the vertical PSD axis range. These off-scale SW2 spectral peaks in reanalyzed MLT winds reveal that the MLT in the $40^{\circ}-50^{\circ} \mathrm{S}$ region encompassing Christchurch was dominated throughout the DEEPWAVE period of June-July 2014 by largeamplitude migrating semidiurnal tides, implying in turn a potential for large semidiurnal tidal modulation of gravity waves observed in the MLT during DEEPWAVE (e.g., Eckermann et al. 2016).

To assess how reliable these reanalyzed MLT tidal wind fields are for DEEPWAVE science applications, Fig. 20 plots time series of the amplitudes and phases of the semidiurnal component resulting from the harmonic fitting procedures applied to time series of meteor radar 


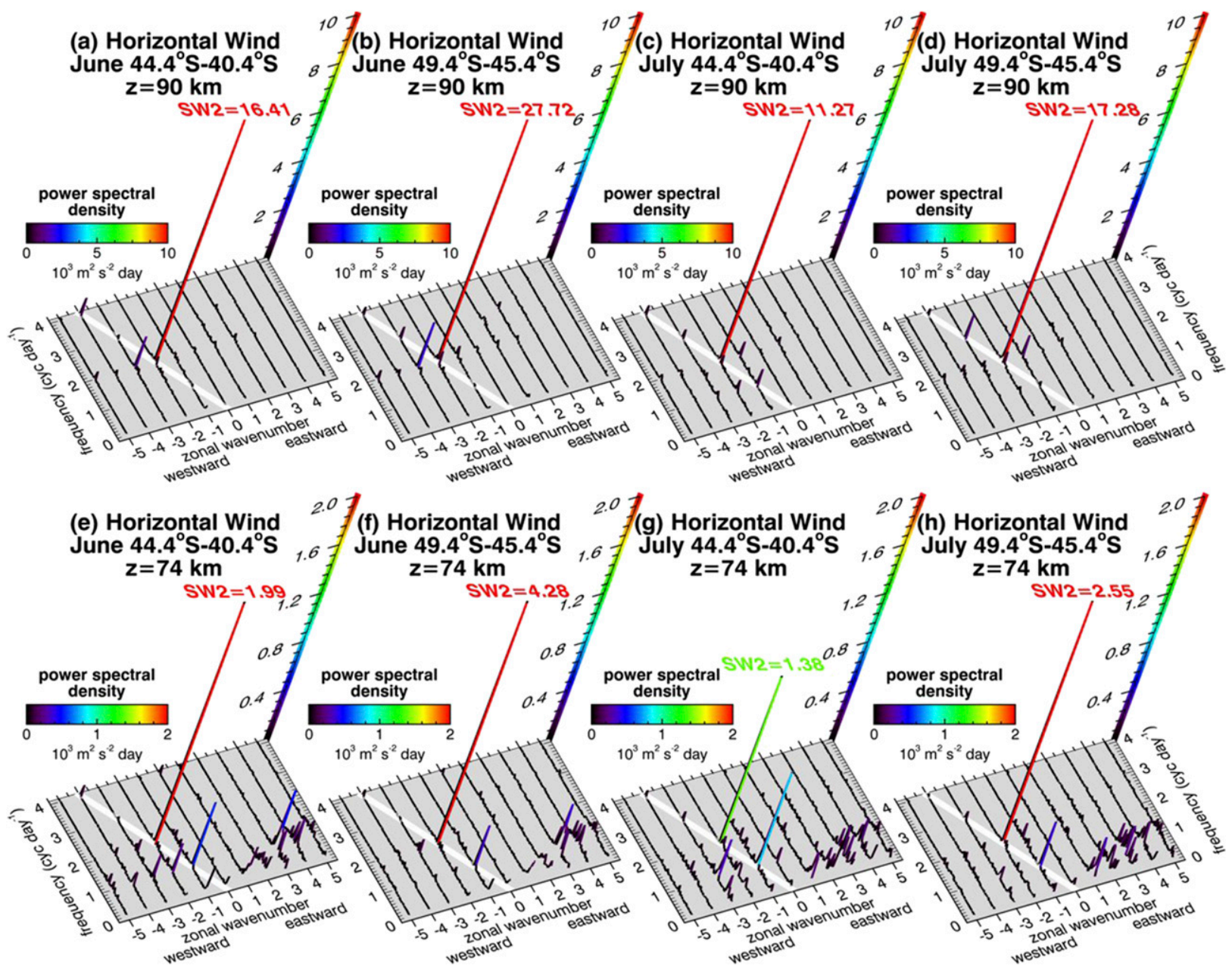

FIG. 19. Mean two-dimensional power spectral densities (see color bars for units) of horizontal winds at (bottom) $z=74$ and (top) $z=90 \mathrm{~km}$. Separate mean spectra are plotted at each height for June and July and for the latitude bands $40.4^{\circ}-44.4^{\circ} \mathrm{S}$ and $45.4^{\circ}-49.4^{\circ} \mathrm{S}$. Zero surface is shaded gray, and modes that migrate with the sun lie along the white line. Low frequencies are masked in these plots to aid visibility of the higher-frequency peaks of interest.

and reanalysis winds over Kingston at $z=88 \mathrm{~km}$. The radar data (black curves) reveal episodically large semidiurnal wind components with amplitudes peaking at up to $40-50 \mathrm{~m} \mathrm{~s}^{-1}$ in both components. Amplitudes, however, vacillate noticeably on $\sim 10-15$-day time scales with tidal amplitudes sometimes becoming very weak.

The colored curves show corresponding results from the various reanalysis time series over Kingston. The NAVGEM reanalyses generally perform well in capturing both the amplification and attenuation of the semidiurnal tidal winds evident in the radar observations. Likewise, the tidal phases in each wind component are captured impressively in the reanalyzed MLT winds.

Time series of the differences between each reanalysis and the radar observations reveal that the HYBRID reanalyses consistently outperform the
4DVAR reanalyses in reproducing observed properties of semidiurnal tidal winds in the MLT, in terms of both phase and amplitude. This is consistent with the better background error covariances in the MLT provided in the HYBRID runs. For example, static geostrophic coupling of observational temperature increments into rotational wind increments in the 4DVAR runs (Fig. 4f) will perform poorly whenever unbalanced (divergent) tidal motions dominate the MLT temperature variability (Fig. 4h).

We conclude from these radar-wind comparisons, as well as the lidar temperature comparisons in Fig. 12, that the NAVGEM HYBRID reanalyses provide reliable estimates of MLT winds and temperatures for assessing how gravity waves observed in the MLT during DEEPWAVE were impacted by migrating semidiurnal tides. 


\section{Meteor Radar $\quad$ HYBRID T119 HYBRID T425 $\quad$ 4DVAR T119 $\quad$ 4DVAR T425}

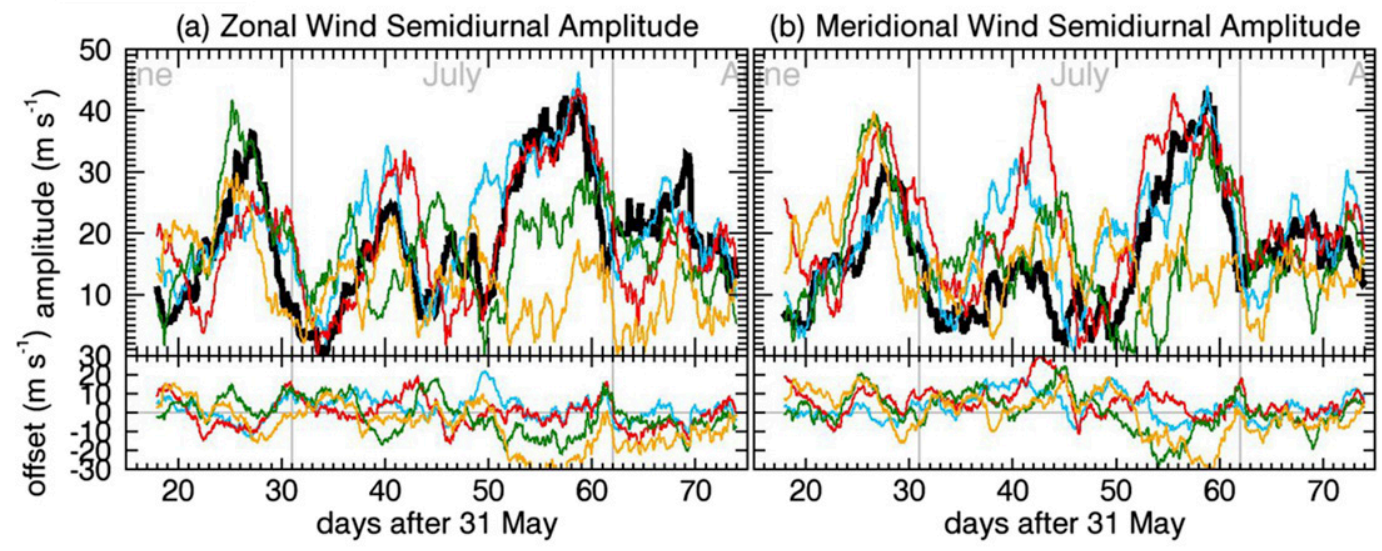

(c) Zonal Wind Semidiurnal Phase

(d) Meridional Wind Semidiurnal Phase

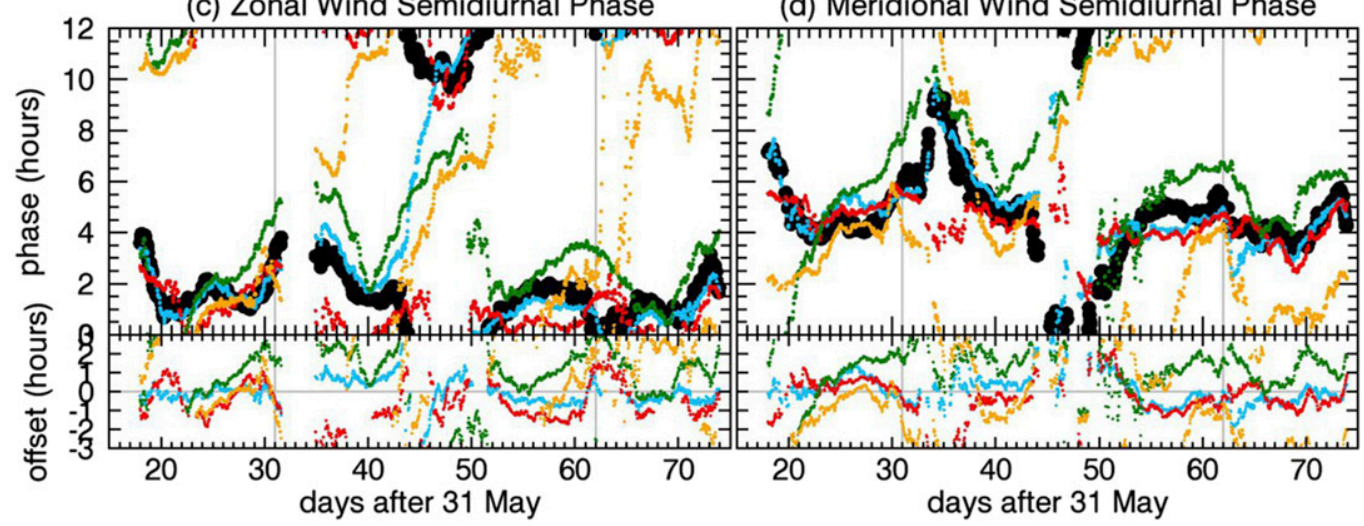

FIG. 20. Plots of semidiurnal tidal features in MLT winds at $z=88 \mathrm{~km}$ over Kingston resulting from $L=4$-day harmonic fits: peak (a) zonal and (b) meridional semidiurnal wind amplitudes $\left(\mathrm{m} \mathrm{s}^{-1}\right)$ and the phase (local time of wind maxima in hours) of (c) zonal and (d) meridional semidiurnal winds. Black curves show fits to meteor radar winds; various colored curves (see color key at top) show fits to the four NAVGEM reanalyses. Smaller panels beneath each main panel show differences of each reanalysis from the meteor radar data. Phase estimates are removed as unreliable wherever meteor radar amplitudes fall below $5 \mathrm{~m} \mathrm{~s}^{-1}$.

\section{Summary and conclusions}

This work has described a vertically extended configuration of NAVGEM developed specifically to address a $\sim 60-100-\mathrm{km}$ reanalysis gap identified as an impediment to MLT science generally and to DEEPWAVE science specifically. To redress the latter, this system was used to generate high-altitude $(0-100 \mathrm{~km})$ atmospheric reanalyses for the austral winter of 2014. A unique feature of these experiments was the assimilation of unprecedented amounts of MLT data (thinned to $\sim 250000$ observations per cycle) having the necessary global and local-time sampling to provide observational information on major planetary waves and tides in the MLT, while retaining NWP-quality reanalysis skill in the troposphere and stratosphere.

Separate reanalysis experiments activated $4 \mathrm{DVAR}$ and hybrid-4DVAR (HYBRID) data assimilation, with each configuration run at both a synoptic (T119/47) and operational (T425/119) horizontal resolution. The four global 0-100-km atmospheric reanalyses that resulted were each compared to independent observations of winds and temperatures in the MLT. Finally, the HYBRID reanalyses were used to study aspects of deep planetary-wave dynamics salient to the gravity wave-focused science goals of DEEPWAVE.

Major scientific findings of this work are as follows:

- 4DVAR reanalyses exhibited systematic warm biases and larger temperature errors in the MLT relative to HYBRID. These differences resulted from prespecified static errors in background MLT temperatures that were too small relative to objective estimates based on standard deviations of reanalyzed temperature differences with respect to independent MLT measurements (SOFIE and DLR lidar). By contrast, HYBRID runs weighted MLT observations and backgrounds more realistically via more representative 
errors in MLT temperature backgrounds from ensemble forecasts (see Fig. 10c). These findings, while specific to the greater New Zealand region during the 2014 austral winter, nevertheless suggest a need to reinvestigate and recalibrate static error variances in NAVGEM for future MLT-focused reanalysis applications.

- HYBRID119 reanalyses revealed substantial reductions in MLT wind errors relative to 4DVAR and HYBRID425. These improvements originated in more realistic coupling of background wind and temperature errors via background error covariances formed from inner-loop ensemble forecasts. Sensitivity tests suggest lesser impacts in HYBRID425 may originate from unpredictable MLT dynamics at high wavenumbers that affect ensemble error covariances.

- Local MLT dynamics during DEEPWAVE were dominated by large-amplitude migrating semidiurnal tides. MLT reanalyses reproduced salient aspects of observed tidal amplitudes and phases, including observed 10-15-day vacillations in tidal wind amplitudes. HYBRID reanalyses outperformed 4DVAR in reproducing observed amplitudes and phases of MLT tidal winds.

- NAVGEM output at 1-h time cadence (i.e., 6-h analysis and $+1-5$-h outer-loop forecasts) substantially increased reanalysis skill relative to use of 6-h analysis alone, due primarily to distortion of semidiurnal tidal structures in the MLT via temporal aliasing at 6-h time cadence.

- Reanalysis winds revealed splitting of the stratopause jet in and around New Zealand in July 2014 due to a large-amplitude, quasi-stationary, wave-1 Rossby wave. The high-altitude reanalysis reveals that while this wave- 1 disturbance dissipated in the upper stratosphere, it reintensified in the MLT, probably via in situ generation via zonal variations in MLT GWD produced by wave-1-induced zonal variations in stratospheric gravity wave filtering.

Based on this work, we have identified HYBRID119 reanalyses as our most reliable MLT reanalysis for distribution to the wider DEEPWAVE science community, where it is already aiding modeling studies of MLT gravity waves observed during DEEPWAVE (Eckermann et al. 2016; Fritts et al. 2018). All NAVGEM reanalysis versions are available to the DEEPWAVE and wider community upon request, and HYBRID119 wind and temperature fields along DEEPWAVE flight tracks are in the process of being uploaded to the DEEPWAVE data archive housed at NCAR's Earth Observing Laboratory (EOL).

The high-altitude NAVGEM described here extends reliable global reanalysis products into the MLT, providing new research insights into global MLT dynamics driven by wave forcing from below. More generally, validated $0-100-\mathrm{km}$ global DAS capabilities within NAVGEM permit future upward extension of the operational NAVGEM to the edge of space at $\sim 100 \mathrm{~km}$, a potential next step toward a future vision of seamless operational terrestrial and space weather prediction (Wang et al. 2012; McDonald et al. 2015).

Acknowledgments. NRL authors acknowledge support of the Chief of Naval Research via the base 6.1, 6.2 , and platform support programs. Generation of NAVGEM reanalyses was made possible by the DoD High-Performance Computer Modernization Program via grants of computer time at the Navy DoD Supercomputing Resource Center. Collection of the Kingston meteor wind data was supported by ATRAD Pty. Ltd. and through Australian Antarctic Science Project 4025. Lidar temperatures, meteor winds, and AVAPS data were made available by NCAR/EOL under the sponsorship of the National Science Foundation via the DEEPWAVE Data Archive Center (https://www.eol. ucar.edu/field_projects/deepwave/). We thank Chris Kruse and two anonymous reviewers for helpful comments on earlier drafts.

\section{REFERENCES}

Allen, D. R., K. W. Hoppel, and D. D. Kuhl, 2014: Wind extraction potential from $4 \mathrm{D}-\mathrm{Var}$ assimilation of stratospheric $\mathrm{O}_{3}, \mathrm{~N}_{2} \mathrm{O}$, and $\mathrm{H}_{2} \mathrm{O}$ using a global shallow water model. Atmos. Chem. Phys., 14, 3347-3360, https://doi.org/10.5194/acp-14-33472014.

,-- , and -2018 : Extraction of wind and temperature information from hybrid 4D-Var assimilation of stratospheric ozone using NAVGEM. Atmos. Chem. Phys., 18, 2999-3026, https://doi.org/10.5194/acp-18-2999-2018.

Baker, N. L., and R. Langland, 2017: Assessing the impact of observations on the prediction of effective atmospheric angular momentum from NAVGEM. Fifth Symp. on the Joint Center for Satellite Data Assimilation, Seattle, WA, Amer. Meteor. Soc., 2.6, https://ams.confex.com/ams/97Annual/webprogram/ Paper304159.html.

Ballish, B., X. Cao, E. Kalnay, and M. Kanamitsu, 1992: Incremental nonlinear normal-mode initialization. Mon. Wea. Rev., 120, 1723-1734, https://doi.org/10.1175/1520-0493(1992) $120<1723$ :INNMI $>2.0 . \mathrm{CO} ; 2$.

Bell, W., and Coauthors, 2008: The assimilation of SSMIS radiances in numerical weather prediction models. IEEE Trans. Geosci. Remote Sens., 46, 884-900, https://doi.org/10.1109/ TGRS.2008.917335.

Bossert, K., and Coauthors, 2015: Momentum flux estimates accompanying multiscale gravity waves over Mount Cook, New Zealand, on 13 July 2014 during the DEEPWAVE campaign. J. Geophys. Res. Atmos., 120, 9323-9337, https:// doi.org/10.1002/2015JD023197,https://doi.org/10.1002/ 2015JA021568. 
Buehner, M., and Coauthors, 2015: Implementation of deterministic weather forecasting systems based on ensemblevariational data assimilation at Environment Canada. Part I: The global system. Mon. Wea. Rev., 143, 2532-2559, https:// doi.org/10.1175/MWR-D-14-00354.1.

Campbell, W. F., E. A. Satterfield, B. Ruston, and N. L. Baker, 2017: Accounting for correlated observation error in a dualformulation 4D variational data assimilation system. Mon. Wea. Rev., 145, 1019-1032, https://doi.org/10.1175/MWR-D16-0240.1.

Chua, B. S., L. Xu, T. Rosmond, and E. D. Zaron, 2009: Preconditioning representer-based variational data assimilation systems: Application to NAVDAS-AR. Data Assimilation for Atmospheric, Oceanic and Hydrologic Applications, S. K. Park and L. Xu, Eds., Springer, 307-319, https://doi.org/ 10.1007/978-3-540-71056-1_16.

Courtier, P., and Coauthors, 1998: The ECMWF implementation of three-dimensional variational assimilation (3D-Var). I: Formulation. Quart. J. Roy. Meteor. Soc., 124, 1783-1807, https://doi.org/10.1002/qj.49712455002.

Daley, R., and E. Barker, 2001a: NAVDAS: Formulation and diagnostics. Mon. Wea. Rev., 129, 869-883, https://doi.org/ 10.1175/1520-0493(2001)129<0869:NFAD>2.0.CO;2.

- , and $-2001 \mathrm{~b}$ : The NAVDAS source book 2001. NRL Publ. NRL/PU/7530-01-441, 163 pp., http://www.dtic.mil/dtic/ tr/fulltext/u2/a396883.pdf.

Dee, D. P., and S. Uppala, 2009: Variational bias correction of satellite radiance data in the ERA-Interim reanalysis. Quart. J. Roy. Meteor. Soc., 135, 1830-1841, https://doi.org/10.1002/ qj.493.

Eckermann, S. D., 2009: Hybrid $\sigma-p$ coordinate choices for a global model. Mon. Wea. Rev., 137, 224-245, https://doi.org/10.1175/ 2008MWR2537.1.

- 2011: Explicitly stochastic parameterization of nonorographic gravity wave drag. J. Atmos. Sci., 68, 1749-1765, https://doi.org/10.1175/2011JAS3684.1.

—_, J. Ma, D. L. Wu, and D. Broutman, 2007: A threedimensional mountain wave imaged in satellite radiance throughout the stratosphere: Evidence of the effects of directional wind shear. Quart. J. Roy. Meteor. Soc., 133, 19591975, https://doi.org/10.1002/qj.187.

__ and Coauthors, 2009: High-altitude data assimilation system experiments for the northern summer mesosphere season of 2007. J. Atmos. Sol.-Terr. Phys., 71, 531-551, https://doi.org/ 10.1016/j.jastp.2008.09.036.

— , J. P. McCormack, J. Ma, T. F. Hogan, and K. A. Zawdie, 2014: Stratospheric analysis and forecast errors using hybrid and sigma coordinates. Mon. Wea. Rev., 142, 476-485, https:// doi.org/10.1175/MWR-D-13-00203.1.

_ observed in the mesosphere over the Auckland Islands during the Deep Propagating Gravity Wave Experiment (DEEPWAVE). J. Atmos. Sci., 73, 3855-3876, https://doi.org/ 10.1175/JAS-D-16-0059.1.

French, W. J. R., and F. J. Mulligan, 2010: Stability of temperatures from TIMED/SABER v1.07 (2002-2009) and Aura/MLS v2.2 (2004-2009) compared with $\mathrm{OH}(6-2)$ temperatures observed at Davis Station, Antarctica. Atmos. Chem. Phys., 10, 11439 11 446, https://doi.org/10.5194/acp-10-11439-2010.

Fritts, D. C., and Coauthors, 2016: The Deep Propagating Gravity Wave Experiment (DEEPWAVE): An airborne and groundbased exploration of gravity wave propagation and effects from their sources throughout the lower and middle atmosphere.
Bull. Amer. Meteor. Soc., 97, 425-453, https://doi.org/10.1175/ BAMS-D-14-00269.1.

—_ and Coauthors, 2018: Large-amplitude mountain waves in the mesosphere accompanying weak cross-mountain flow during DEEPWAVE research flight RF22.J. Geophys. Res., in press.

García-Comas, M., and Coauthors, 2014: MIPAS temperature from the stratosphere to the lower thermosphere: Comparison of vM21 with ACE-FTS, MLS, OSIRIS, SABER, SOFIE and lidar measurements. Atmos. Meas. Tech., 7, 3633-3651, https:// doi.org/10.5194/amt-7-3633-2014.

Gauthier, P., and J. N. Thépaut, 2001: Impact of the digital filter as a weak constraint in the preoperational $4 \mathrm{DVAR}$ assimilation system of Météo-France. Mon. Wea. Rev., 129, 2089-2102, https://doi.org/10.1175/1520-0493(2001)129<2089: IOTDFA>2.0.CO;2.

Gelaro, R., and Coauthors, 2017: The Modern-Era Retrospective Analysis for Research and Applications, version 2 (MERRA-2). J. Climate, 30, 5419-5454, https://doi.org/ 10.1175/JCLI-D-16-0758.1.

Gisinger, S., and Coauthors, 2017: Atmospheric conditions during the Deep Propagating Gravity Wave Experiment (DEEPWAVE). Mon. Wea. Rev., 145, 4249-4275, https:// doi.org/10.1175/MWR-D-16-0435.1.

Gordley, L. L., and Coauthors, 2009: The Solar Occultation for Ice Experiment. J. Atmos. Sol.-Terr. Phys., 71, 300-315, https:// doi.org/10.1016/j.jastp.2008.07.012.

Guest, F. M., M. J. Reeder, C. J. Marks, and D. J. Karoly, 2000: Inertia-gravity waves observed in the lower stratosphere over Macquarie Island. J. Atmos. Sci., 57, 737-752, https://doi.org/ 10.1175/1520-0469(2000)057<0737:IGWOIT>2.0.CO;2.

Han, Y., P. van Delst, and F. Weng, 2010: An improved fast radiative transfer model for special sensor microwave imager/ sounder upper atmosphere sounding channels. J. Geophys. Res., 115, D15109, https://doi.org/10.1029/2010JD013878.

Hogan, T. F., and Coauthors, 2014: The Navy Global Environmental Model. Oceanography, 27, 116-125, https://doi.org/ 10.5670/oceanog.2014.73.

Holdsworth, D. A., I. M. Reid, and M. Cervera, 2004: Buckland Park all-sky interferometric meteor radar. Radio Sci., 39, RS5009, https://doi.org/10.1029/2003RS003014.

Hoover, B. T., and R. H. Langland, 2016: NAVGEM forecast and observation impact experiments with assimilation of ECWMF analysis data in the global domain. NRL Memo. Rep. NRL/MR/7531-16-9693, 37 pp., https://doi.org/10.13140/ RG.2.2.32127.82083.

Hoppel, K. W., N. L. Baker, L. Coy, S. D. Eckermann, J. P. McCormack, G. E. Nedoluha, and D. E. Siskind, 2008: Assimilation of stratospheric and mesospheric temperatures from MLS and SABER into a global NWP model. Atmos. Chem. Phys., 8, 6103-6116, https://doi.org/10.5194/acp-8-6103-2008.

— S. D. Eckermann, L. Coy, G. E. Nedoluha, D. R. Allen, S. D. Swadley, and N. L. Baker, 2013: Evaluation of SSMIS upper atmosphere sounding channels for high-altitude data assimilation. Mon. Wea. Rev., 141, 3314-3330, https://doi.org/ 10.1175/MWR-D-13-00003.1.

Hortal, M., and A. J. Simmons, 1991: Use of reduced Gaussian grids in spectral models. Mon. Wea. Rev., 119, 1057-1074, https://doi.org/10.1175/1520-0493(1991)119<1057:UORGGI> 2.0.CO;2.

Kaifler, B., and N. Kaifler, 2016: Project DEEPWAVE DLR Lauder Rayleigh-Raman lidar data, version 3. UCAR/NCAR Earth Observing Laboratory, accessed 19 August 2017, https:// doi.org/10.5065/d67p8wrn. 
,-- , B. Ehard, A. Dörnbrack, M. Rapp, and D. C. Fritts, 2015: Influences of source conditions on mountain wave penetration into the stratosphere and mesosphere. Geophys. Res. Lett., 42, 9488-9494, https://doi.org/10.1002/2015GL066465.

Koshyk, J. N., B. A. Boville, K. Hamilton, E. Manzini, and K. Shibata, 1999: Kinetic energy spectrum of horizontal motions in middle-atmosphere models. J. Geophys. Res., 104, 27 177-27 190, https://doi.org/10.1029/1999JD900814.

Kuhl, D. D., T. E. Rosmond, C. H. Bishop, J. McLay, and N. L. Baker, 2013: Comparison of hybrid ensemble/4DVar and 4DVar within the NAVDAS-AR data assimilation framework. Mon. Wea. Rev., 141, 2740-2758, https://doi.org/10.1175/ MWR-D-12-00182.1.

Kunkee, D. B., G. A. Poe, D. J. Boucher, S. D. Swadley, Y. Hong, J. E. Wessel, and E. A. Uliana, 2008: Design and evaluation of the first Special Sensor Microwave Imager/Sounder. IEEE Trans. Geosci. Remote Sens., 46, 863-883, https://doi.org/ 10.1109/TGRS.2008.917980.

Lambert, A., and Coauthors, 2007: Validation of the Aura Microwave Limb Sounder middle atmosphere water vapor and nitrous oxide measurements. J. Geophys. Res., 112, D24S36, https://doi.org/10.1029/2007JD008724.

Lane, T. P., M. J. Reeder, B. R. Morton, and T. L. Clark, 2000: Observations and numerical modelling of mountain waves over the Southern Alps of New Zealand. Quart. J. Roy. Meteor. Soc., 126, 2765-2788, https://doi.org/10.1002/qj.49712656909.

Laursen, K. K., D. P. Jorgensen, G. P. Brasseur, S. L. Ustin, and J. R. Huning, 2006: HIAPER: The next generation NSF/ NCAR research aircraft. Bull. Amer. Meteor. Soc., 87, 896910, https://doi.org/10.1175/BAMS-87-7-896.

Liu, H.-L., F. Sassi, and R. R. Garcia, 2009: Error growth in a whole atmosphere climate model. J. Atmos. Sci., 66, 173-186, https:// doi.org/10.1175/2008JAS2825.1.

Long, D. J., D. R. Jackson, J. Thuburn, and C. Mathison, 2013: Validation of Met Office upper stratospheric and mesospheric analyses. Quart. J. Roy. Meteor. Soc., 139, 1214-1228, https:// doi.org/10.1002/qj.2031.

Lorenc, A. C., 1981: A global three-dimensional multivariate statistical interpolation scheme. Mon. Wea. Rev., 109, 701-721, https://doi.org/10.1175/1520-0493(1981)109<0701: AGTDMS $>2.0 . \mathrm{CO} ; 2$.

Lynch, P., and X.-Y. Huang, 1992: Initialization of the HIRLAM model using a digital filter. Mon. Wea. Rev., 120, 10191034, https://doi.org/10.1175/1520-0493(1992)120<1019: IOTHMU $>2.0 . \mathrm{CO} ; 2$.

Marsh, D. R., R. R. Garcia, D. E. Kinnison, B. A. Boville, F. Sassi, S. C. Solomon, and K. Matthes, 2007: Modeling the whole atmosphere response to solar cycle changes in radiative and geomagnetic forcing. J. Geophys. Res., 112, D23306, https:// doi.org/10.1029/2006JD008306.

Marshall, B. T., L. E. Deaver, R. E. Thompson, L. L. Gordley, M. J. McHugh, M. E. Hervig, and J. M. Russell III, 2011: Retrieval of temperature and pressure using broadband solar occultation: SOFIE approach and results. Atmos. Meas. Tech., 4, 893907, https://doi.org/10.5194/amt-4-893-2011.

Maurer, T., B. Ruston, S. D. Swadley, and A. Booton, 2015: Assimilation impacts of SSMIS upper atmosphere soundings with improved orbital bias predictors in NAVGEM. 20th Int. TOVS Study Conf., Lake Geneva, WI, International TOVS Working Group, 11.03, https://cimss.ssec.wisc.edu/itwg/itsc/ itsc20/program/PDFs/2Nov/session11a/11_03_maurer.pdf.

McCormack, J. P., and Coauthors, 2017: Comparison of mesospheric winds from a high-altitude meteorological analysis system and meteor radar observations during the boreal winters of 2009-2010 and 2012-2013. J. Atmos. Sol.-Terr. Phys., 154, 132-166, https://doi.org/10.1016/j.jastp.2016.12.007.

McDonald, S. E., F. Sassi, and A. J. Mannucci, 2015: SAMI3/ SD-WACCM-X simulations of ionospheric variability during northern winter 2009. Space Wea., 13, 568-584, https://doi.org/ 10.1002/2015SW001223.

McLandress, C., W. E. Ward, V. I. Fomichev, K. Semeniuk, S. R. Beagley, N. A. McFarlane, and T. G. Shepherd, 2006: Large-scale dynamics of the mesosphere and lower thermosphere: An analysis using the extended Canadian Middle Atmosphere Model. J. Geophys. Res., 111, D17111, https:// doi.org/10.1029/2005JD006776.

McLay, J., C. H. Bishop, and C. A. Reynolds, 2010: A local formulation of the ensemble transform (ET) analysis perturbation scheme. Wea. Forecasting, 25, 985-993, https://doi.org/ 10.1175/2010WAF2222359.1.

Nezlin, Y., S. Polavarapu, and Y. J. Rochon, 2009a: A new method of assessing filtering schemes in data assimilation systems. Quart. J. Roy. Meteor. Soc., 135, 1059-1070, https://doi.org/ 10.1002/qj.418.

—, Y. J. Rochon, and S. Polavarapu, 2009b: Impact of tropospheric and stratospheric data assimilation on mesospheric prediction. Tellus, 61A, 154-159, https://doi.org/10.1111/ j.1600-0870.2008.00368.x.

Pautet, P.-D., and Coauthors, 2016: Large-amplitude mesospheric response to an orographic wave generated over the Southern Ocean Auckland Islands $\left(50.7^{\circ} \mathrm{S}\right)$ during the DEEPWAVE project. J. Geophys. Res. Atmos., 121, 1431-1441, https:// doi.org/10.1002/2015JD024336.

Polavarapu, S., S. Z. Ren, Y. Rochon, D. Sankey, N. Ek, J. Koshyk, and D. Tarasick, 2005: Data assimilation with the Canadian middle atmosphere model. Atmos.-Ocean, 43, 77-100, https:// doi.org/10.3137/ao.430105.

Reeder, M. J., N. Adams, and T. P. Lane, 1999: Radiosonde observations of partially trapped lee waves over Tasmania, Australia. J. Geophys. Res., 104, 16 719-16 727, https://doi.org/ 10.1029/1999JD900038.

Reid, I. M., D. A. Holdsworth, R. J. Morris, D. J. Murphy, and R. A. Vincent, 2006: Meteor observations using the Davis mesosphere-stratosphere-troposphere radar.J. Geophys. Res., 111, A05305, https://doi.org/10.1029/2005JA011443.

D. M. Murphy, A. Mackinnon, A. Spargo, P. Love, and C. Adami, 2015: Meteor radar winds, Kingston, Tasmania. Version 1.0. UCAR/NCAR Earth Observing Laboratory, accessed 24 May 2017, https://data.eol.ucar.edu/dataset/ 379.043.

Remsberg, E. E., and Coauthors, 2008: Assessment of the quality of the version 1.07 temperature-versus-pressure profiles of the middle atmosphere from TIMED/SABER. J. Geophys. Res., 113, D17101, https://doi.org/10.1029/2008JD010013.

Ren, S., S. M. Polavarapu, and T. G. Shepherd, 2008: Vertical propagation of information in a middle atmosphere data assimilation system by gravity-wave drag feedbacks. Geophys. Res. Lett., 35, L06804, https://doi.org/10.1029/ 2007GL032699.

- — - S. R. Beagley, Y. Nezlin, and Y. J. Rochon, 2011: The impact of gravity wave drag on mesospheric analyses of the 2006 stratospheric major warming. J. Geophys. Res., 116, D19116, https://doi.org/10.1029/2011JD015943.

Reynolds, C. A., J. G. McLay, J. S. Goerss, E. A. Serra, D. Hodyss, and C. R. Sampson, 2011: Impact of resolution and design on the U.S. Navy global ensemble performance in the tropics. 
Mon. Wea. Rev., 139, 2145-2155, https://doi.org/10.1175/ 2011MWR3546.1.

Rezac, L., A. Kutepov, J. M. Russell III, A. G. Feofilov, J. Yue, and R. A. Goldberg, 2015: Simultaneous retrieval of $T(p)$ and $\mathrm{CO}_{2}$ VMR from two-channel non-LTE limb radiances and application to daytime SABER/TIMED measurements. J. Atmos. Sol.-Terr. Phys., 130-131, 23-42, https://doi.org/10.1016/ j.jastp.2015.05.004.

Rienecker, M. M., and Coauthors, 2011: MERRA: NASA's Modern-Era Retrospective Analysis for Research and Applications. J. Climate, 24, 3624-3648, https://doi.org/10.1175/ JCLI-D-11-00015.1.

Rosmond, T. E., 1997: A technical description of the NRL Adjoint Modeling System. NRL Memo. Rep. NRL/MR/7532/97/7230, 53 pp., http://www.dtic.mil/dtic/tr/fulltext/u2/a330960.pdf.

Sankey, D., S. Ren, S. Polavarapu, Y. J. Rochon, Y. Nezlin, and S. Beagley, 2007: Impact of data assimilation filtering methods on the mesosphere. J. Geophys. Res., 112, D24104, https:// doi.org/10.1029/2007JD008885.

Schwartz, M. J., and Coauthors, 2008: Validation of the Aura Microwave Limb Sounder temperature and geopotential height measurements. J. Geophys. Res., 113, D15S11, https://doi.org/ 10.1029/2007JD008783.

Seaman, R., W. Bourke, P. Steinle, T. Hart, G. Embery, M. Naughton, and L. Rikus, 1995: Evolution of the Bureau of Meteorology's global assimilation and prediction system. 1. Analysis and initialization. Aust. Meteor. Mag., 44, 1-18, http:// www.bom.gov.au/amm/papers.php? year $=1995$.

Smith, A. K., 2003: The origin of stationary planetary waves in the upper mesosphere. J. Atmos. Sci., 60, 3033-3041, https:// doi.org/10.1175/1520-0469(2003)060<3033:TOOSPW > 2.0.CO;2.

Smith, S. A., D. C. Fritts, and T. E. Vanzandt, 1987: Evidence for a saturated spectrum of atmospheric gravity waves. J. Atmos. Sci., 44, 1404-1410, https://doi.org/10.1175/1520-0469(1987) 044<1404:EFASSO > 2.0.CO;2.

Smith, S. M., S. L. Vadas, W. J. Baggaley, G. Hernandez, and J. Baumgardner, 2013: Gravity wave coupling between the mesosphere and thermosphere over New Zealand. J. Geophys. Res. Space Phys., 118, 2694-2707, https://doi.org/10.1002/ jgra.50263.
Swadley, S. D., G. A. Poe, W. Bell, Y. Hong, D. B. Kunkee, S. McDermid, and T. Leblanc, 2008: Analysis and characterization of the SSMIS upper atmosphere sounding channel measurements. IEEE Trans. Geosci. Remote Sens., 46, 962 983, https://doi.org/10.1109/TGRS.2008.916980.

Wang, H., T. J. Fuller-Rowell, R. A. Akmaev, M. Hu, D. T. Kleist, and M. D. Iredell, 2012: First simulations with a whole atmosphere data assimilation and forecast system: The January 2009 major sudden stratospheric warming. J. Geophys. Res., 116, A12321, https://doi.org/10.1029/ 2011JA017081; Correction, 117, A03326, https://doi.org/ 10.1029/2012JA017630.

Webster, S., A. R. Brown, D. R. Cameron, and C. P. Jones, 2003: Improvements to the representation of orography in the Met Office Unified Model. Quart. J. Roy. Meteor. Soc., 129, 19892010, https://doi.org/10.1256/qj.02.133.

Wergen, W., 1989: Normal mode initialization and atmospheric tides. Quart. J. Roy. Meteor. Soc., 115, 535-545, https://doi.org/ 10.1002/qj.49711548706.

Xu, L., T. Rosmond, and R. Daley, 2005: Development of NAVDAS-AR: Formulation and initial tests of the linear problem. Tellus, 57A, 546-559, https://doi.org/10.3402/tellusa. v57i4.14710.

$\longrightarrow, \ldots$, J. Goerss, and B. Chua, 2007: Toward a weak constraint operational 4D-Var system: Application to the Burgers' equation. Meteor. Z., 16, 741-753, https://doi.org/10.1127/ 0941-2948/2007/0246.

Yan, X., J. S. Wright, X. Zheng, N. J. Livesey, H. Vömel, and X. Zhou, 2016: Validation of Aura MLS retrievals of temperature, water vapour and ozone in the upper troposphere and lower-middle stratosphere over the Tibetan Plateau during boreal summer. Atmos. Meas. Tech., 9, 3547-3566, https://doi.org/10.5194/amt-9-3547-2016.

Young, K., T. Hock, and C. Martin, 2016: DEEPWAVE 2014 dropsonde data quality report, version 3.0. UCAR/NCAR Earth Observing Laboratory Tech. Rep., 11 pp., https:// doi.org/10.5065/D6XW4GTB.

Zink, F., and R. A. Vincent, 2001: Wavelet analysis of stratosphere gravity wave packets over Macquarie Island: 1 . Wave parameters. J. Geophys. Res., 106, 10 275-10 288, https://doi.org/ 10.1029/2000JD900847. 